\title{
Subthalamic Nucleus Lesions: Widespread Effects on Changes in Gene Expression Induced by Nigrostriatal Dopamine Depletion in Rats
}

\author{
Jill M. Delfs, Vivian M. Ciaramitaro, Tom J. Parry, ${ }^{a}$ and Marie-Francoise Chesselet \\ Department of Pharmacology and David Mahoney Institute of Neurological Sciences, University of Pennsylvania \\ School of Medicine, Philadelphia, Pennsylvania 19104
}

\begin{abstract}
Lesions of the subthalamic nucleus block behavioral effects of nigrostriatal dopamine depletion in rats and primates, but the contribution of this region to the molecular effects of dopaminergic lesions is unknown. The effects of subthalamic nucleus lesions alone or in combination with a 6-hydroxydopamine-induced lesion of the substantia nigra were examined in adult rats. Unilateral subthalamic nucleus lesions caused ipsiversive rotation after peripheral administration of apomorphine and a small decrease in glutamic acid decarboxylase (GAD) mRNA in the ipsilateral globus pallidus (external pallidum). Confirming previous results, nigrostriatal dopaminergic lesions caused contraversive rotation after apomorphine injection, and increased enkephalin mRNA in the striatum, GAD mRNA in the globus pallidus, and somatostatin mRNA in the entopeduncular nucleus (internal pallidum) ipsilateral to the lesion. In addition, the lesion decreased substance P mRNA in the ipsilateral striatum compared to the contralateral side, and GAD mRNA in the contralateral entopeduncular nucleus. These effects were abolished in rats with lesions of the subthalamic nucleus and substantia nigra on the same side. Thus, the subthalamic lesion prevented changes in gene expression induced by dopamine depletion, not only in regions receiving a direct input from the subthalamic nucleus (ipsilateral pallidum), but also in regions which do not (striatum and contralateral pallidum). This suggests that polysynaptic pathways regulated by the subthalamic nucleus contribute to the effects of dopaminergic lesions in many regions of the basal ganglia. This pivotal role of the subthalamic nucleus may account for the beneficial effects of subthalamic nucleus lesions on motor symptoms resulting from dopamine depletion.
\end{abstract}

[Key words: subthalamic nucleus, 6-hydroxydopamine, globus pallidus, entopeduncular nucleus, basal ganglia, in situ hybridization, glutamic acid decarboxylase]

\footnotetext{
Received Apr. 12, 1995; revised May 23, 1995; accepted May 24, 1995.

This work was supported by U.S. Public Health Service Grant MH 44894 (M.F.C) and Training Grants MH 17168 (J.M.D.) and MH 14654 (T.J.P.). We gratefully appreciate the generosity of Drs. Richard Goodman (Vollum Institute), James Krause (Washington University), Steven Sabol (NIMH), and Allan Tobin (UCLA) for providing the cDNAs used in these studies.

Correspondence should be addressed to Marie-Françoise Chesselet, M.D. Ph.D., University of Pennsylvania School of Medicine, Department of Pharmacology, 3620 Hamilton Walk, Philadelphia, PA 19104.

"Present address: Zynaxis, Inc., Malvern, PA 19355

Copyright (C) 1995 Society for Neuroscience $0270-6474 / 95 / 156562-14 \$ 05.00 / 0$
}

The subthalamic nucleus has recently gained recognition as a major excitatory drive in the basal ganglia (Kitai and Kita, 1987; Féger et al., 1991; Parent and Hazrati, 1995). This region consists of a small collection of glutamatergic neurons located above the cerebral peduncle (Smith and Parent, 1988; Rinvik and Ottersen, 1993). The subthalamic nucleus projects to the pallidum and substantia nigra pars reticulata, two main target areas of striatal output neurons. Therefore, it is in a strategic position to govern the outflow of motor information from the basal ganglia (Deniau et al., 1978; Nauta and Cole, 1978; Kita and Kitai, 1987; Parent and Smith, 1987; Takada et al., 1988; Smith et al., 1990; Berendse and Groenewegen, 1991). Accordingly, lesions or high-frequency stimulation of the subthalamic nucleus alleviate motor symptoms induced by nigrostriatal dopamine depletion (Bergman et al., 1990; Aziz et al., 1991; Benazzouz et al., 1993; Limousin et al., 1995).

According to current models of basal ganglia circuitry, changes in the activity of both direct and indirect inputs from the striatum to the internal pallidum and the substantia nigra pars reticulata are critical for hypokinctic movement disordcrs, such as akinesia in Parkinson's disease (Albin et al., 1989; DeLong, 1990). Indirect inputs from the striatum reach the internal pallidum and substantia nigra via the external pallidum and the subthalamic nucleus. Thus, according to this model, the subthalamic nucleus acts primarily as a relay between the external pallidum and the internal pallidum/substantia nigra in the indirect pathway.

The subthalamic nucleus, however, also sends reciprocal projections to the external pallidum (Deniau et al., 1978; Nauta and Cole, 1978; Van der Kooy and Hattori, 1980; Kita and Kitai, 1987; Takada et al., 1988; Smith et al., 1990). Supporting a functional role for this pathway, pharmacological stimulation and lesions of the subthalamic nucleus alter neuronal firing in the external pallidum (Ryan and Sanders, 1993; Soltis et al., 1994). In rats and primates, nigrostriatal lesions increase burst firing activity and the levels of mRNA for glutamic acid decarboxylase $\left(M_{r} 67,000\right.$; GAD67), the enzyme of GABA synthesis, in the external pallidum (Filion, 1979; Miller and DeLong, 1987; Pan and Walters, 1988; Filion and Tremblay, 1991; Kincaid et al., 1992; Soghomonian and Chesselet, 1992; Herrero et al., 1993; Soghomonian et al., 1994). We have previously proposed (Soghomonian and Chesselet, 1992; see also Kincaid et al., 1992) that these effects result from the increased activity of subthalamic neurons observed after nigrostriatal lesions (Miller and DeLong, 1987; Féger et al., 1991; Robledo and Féger, 1991; Hollerman and Grace, 1992; Bergman et al., 1994). 


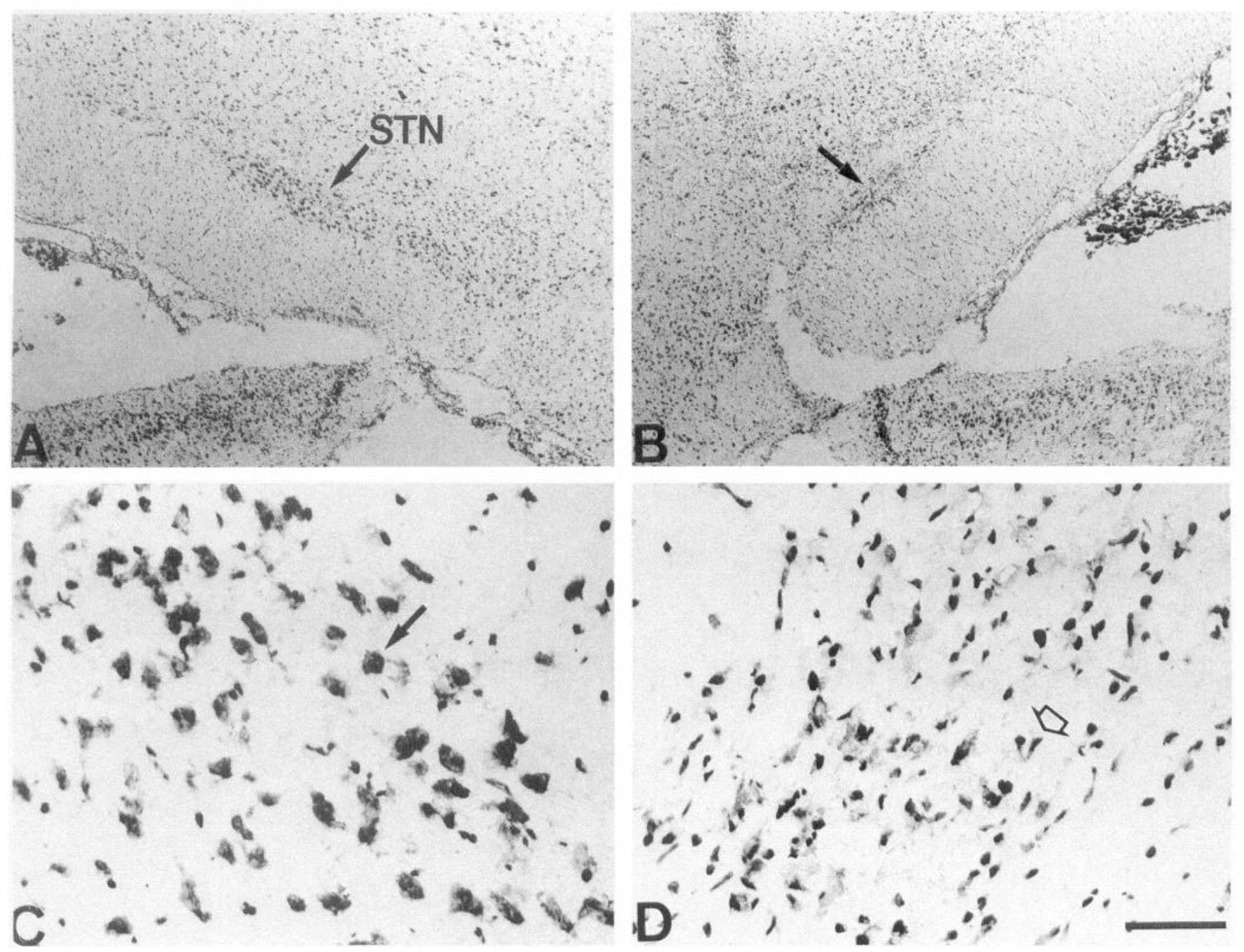

Figure 1. Bright-field photomicrographs of cresyl violet-stained sections illustrating a unilateral kainic acid lesion of the subthalamic nucleus. Rats received a unilateral infusion of kainic acid $(0.5 \mathrm{nmol}$ in $0.1 \mu \mathrm{l})$ and were sacrificed $21 \mathrm{~d}$ later. Low-power photomicrograph illustrating $(A)$ the intact subthalamic nucleus (STN) contralateral to the lesion and $(B)$ the kainic acid-lesioned subthalamic nucleus $(a r r o w)$. $C$, High-power photomicrograph of intact subthalamic nucleus neurons (arrow) depicted in $A$. D. High-power photomicrograph of the lesioned subthalamic nucleus depicted in $B$. Note the neuronal loss and extensive gliosis (glial cell, open arrow) induced by local infusion of kainic acid into the subthalamic nucleus. Scale bars: $A$ and $B, 500 \mu \mathrm{m} ; C$ and $D, 50 \mu \mathrm{m}$.

To test this hypothesis, we have examined the effects of unilateral lesions of the subthalamic nucleus, alone or in combination with a 6-hydroxydopamine (6-OHDA)-induced lesion of the substantia nigra, on the level of expression of GAD67 mRNA in the globus pallidus (external pallidum) in rats. In addition, we investigated the role of the subthalamic nucleus in other changes in neurotransmitter-related gene expression observed in striatum and pallidum after nigrostriatal lesions.

\section{Materials and Methods}

Animals and tissue preparation. Forty adult male Sprague-Dawley rats (Charles River Laboratories, Wilmington, MA; initial weight 280-300 gm) were used for the following experiments. Upon arrival, animals were handled, weighed and subsequently housed in groups of three until surgical procedures were performed. Rats were maintained on a $12 \mathrm{hr} /$ $12 \mathrm{hr}$ light/dark cycle (lights on from 07:00 to 19:00) with food and water available ad libitum. All surgical procedures and behavioral testing were performed between 08:00 and 14:00 hr, during the light cycle. All procedures were done in accordance with the NIH Guide for the Care and Use of Laboratory Animals and were approved by the local animal care committee. All surgical procedures were performed under anesthesia with equithesin at a dose of $0.3 \mathrm{ml}$ per $100 \mathrm{gm}$ of body weight (prepared following the protocol of Jensen-Salbutry Laboratories, Kansas City, MO).

Twenty rats designated as controls received an injection of $0.1 \mu \mathrm{l}$ of $0.9 \%$ sterile saline into the left subthalamic nucleus. Twenty rats received an injection of $0.5 \mathrm{nmol}$ of the neurotoxin kainic acid (Sigma Chemical Co., St. Louis, MO) dissolved in $0.1 \mu \mathrm{l}$ of $0.9 \%$ sterile saline into the left subthalamic nucleus. All injections were performed over $48 \mathrm{sec}$ and the cannula was left in place for an additional $5 \mathrm{~min}$ to allow for diffusion. The stereotaxic coordinates of the injection were AP: $4.9 \mathrm{~mm}$ from interaural zero; ML: $2.5 \mathrm{~mm}$ from midline; DV: -7.4 $\mathrm{mm}$ from the dura based on the atlas of Paxinos and Watson (1986). While recovering from anesthesia, rats with kainic acid injections in the subthalamic nucleus, but not the saline-injected controls, exhibited stereotyped extension-flexion movements of the contralateral forelimb, orofacial dyskinesias consisting of vacuous chewing and jaw tremors, postural asymmetry toward the intact side, and spontaneous contraversive circling. These behaviors gradually subsided during the 4-6 hr postoperative period.

Six days after the subthalamic nucleus lesions, 10 kainic acid-lesioned animals and 10 control animals received an injection of $8 \mu \mathrm{g}$ of the neurotoxin 6-hydroxydopamine (6-OHDA, bromide salt, Sigma Chemical Co., St. Louis, MO) dissolved in $4 \mu \mathrm{l}$ of $0.9 \%$ sterile saline containing $1 \%$ ascorbic acid over $2 \mathrm{~min}$ into the left substantia nigra. The stereotaxic coordinates of the injection site were AP: $3.4 \mathrm{~mm}$ from 

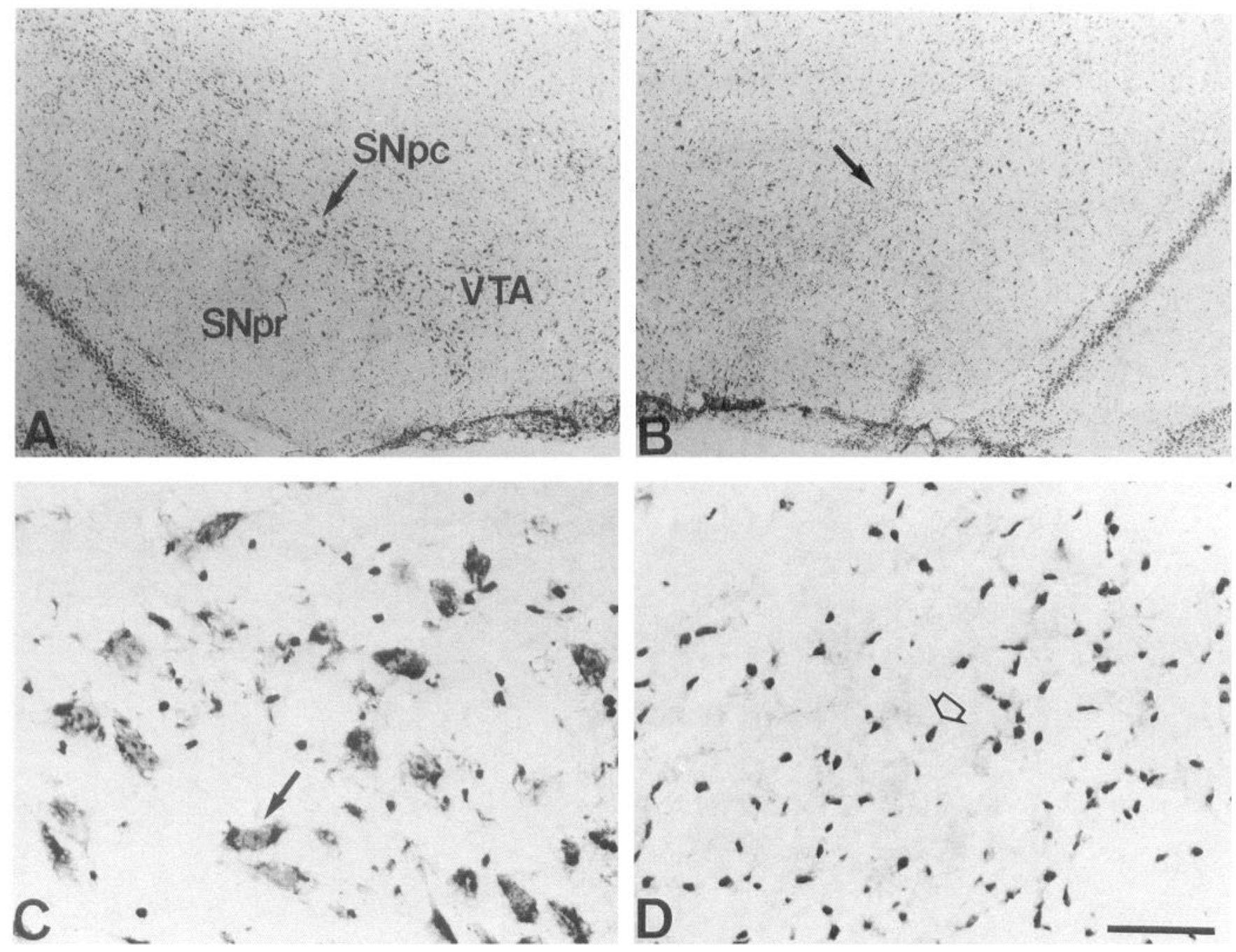

Figure 2. Bright-field photomicrographs of cresyl violet-stained sections illustrating a unilateral 6-hydroxydopamine (6-OHDA) lesion of the substantia nigra pars compacta. Rats received a unilateral infusion of 6-OHDA ( $8 \mu \mathrm{g}$ in $4 \mu \mathrm{l})$ and were sacrificed $14 \mathrm{~d}$ later. Low-power photomicrographs of $(A)$ the intact substantia nigra pars compacta $(S N p c)$ contralateral to the lesion and $(B)$ the 6-OHDA lesioned substantia nigra (arrow). Note that there is some damage to the adjacent ventral tegmental area $(V T A)$, but that the underlying substantia nigra pars reticulata ( $S N p r)$ is unaffected by the lesion in $B$ compared to control $(A)$. High-power photomicrographs of $(C)$ the intact substantia nigra pars compacta and $(D)$ the lesioned substantia nigra pars compacta illustrate the complete loss of dopaminergic neurons (arrow in $C$ ) and extensive gliosis (open arrow in $D$ ). Scale bars: $A$ and $B, 500 \mu \mathrm{m} ; C$ and $D, 50 \mu \mathrm{m}$.

interaural zero; ML: $2.0 \mathrm{~mm}$ from midline; $\mathrm{DV}:+2.2 \mathrm{~mm}$ from the interaural zero, based on the atlas of Paxinos and Watson (1986). Thirty minutes before the stereotaxic injection into the substantia nigra, all rats received an injection of desipramine $(25 \mathrm{mg} / \mathrm{kg}$, s.c., Sigma Chemical Co., St. Louis, MO) to protect noradrenergic neurons (Wooten and Collins 1981). The remaining 20 rats received an injection of $4 \mu \mathrm{l}$ of $0.9 \%$ sterile saline, $0.1 \%$ ascorbic acid into the substantia nigra after pretreatment with desipramine. To select rats with appropriate lesions, all animals received a subcutaneous injection of apomorphine $(0.5 \mathrm{mg} / \mathrm{kg}$, s.c., Sigma Chemical Co., St. Louis, MO) $8 \mathrm{~d}$ after the 6-OHDA lesions of the substantia nigra to test for turning behavior as an index of the extent of the lesion of dopaminergic neurons (Hudson et al., 1993).

All four groups of rats were sacrificed by decapitation one week after behavioral testing. Thus, the groups are as follows: control rats which received sham injections into the subthalamic nucleus and substantia nigra, rats sacrificed $21 \mathrm{~d}$ after a unilateral kainic acid lesion of the subthalamic nucleus, rats sacrificed $14 \mathrm{~d}$ after a unilateral 6-OHDA lesion of the substantia nigra, and rats with combined lesions sacrificed $21 \mathrm{~d}$ after a subthalamic nucleus lesion and $14 \mathrm{~d}$ after a substantia nigra lesion. After decapitation, the brains were rapidly removed, frozen on powdered dry ice and stored at $-70^{\circ} \mathrm{C}$ until processing. Brains were cut into $10 \mu \mathrm{m}$ sections with a Reichert-Jung cryostat, thaw mounted onto gelatin-coated slides, and stored at $-70^{\circ} \mathrm{C}$ until use. Sections from the substantia nigra and subthalamic nucleus were stained either with hematoxylin and eosin or with cresyl violet and observed with bright field microscopy to assess the location and extent of the lesions.

${ }^{3} \mathrm{H}-\mathrm{BTCP}$ receptor autoradiography for dopamine uptake sites. In order to assess the extent of the lesion of dopamine terminals in the striatum, the loss of dopamine uptake sites was determined by autoradiography with the selective ligand ${ }^{3} \mathrm{H}-\mathrm{N}-[1-92$-benzo(b)thiophenyl)cyclohexyl]-piperidine (BTCP) (Vignon et al., 1988). Using a protocol modified from Filloux et al. (1989), slides containing sections of the striatum were brought to room temperature from $-70^{\circ} \mathrm{C}$ under a stream of cool air and were preincubated in ice cold $50 \mathrm{~mm}$ Tris $\mathrm{HCl}$ buffer containing $200 \mathrm{mM} \mathrm{NaCl}, \mathrm{pH} 7.0$ at $4^{\circ} \mathrm{C}$ for $20 \mathrm{~min}$ to remove endogenous dopamine. This was followed by incubation in the same buffer as above containing $2 \mathrm{nM}{ }^{3} \mathrm{H}-\mathrm{BTCP}$ (NEN/Du Pont, Boston, MA, specific activity $49 \mathrm{Ci} / \mathrm{mmol}$ ) at $4^{\circ} \mathrm{C}$ for $90 \mathrm{~min}$. Nonspecific binding was determined by the addition of $10 \mu \mathrm{M}$ GBR 12909 (Research Biochemicals Inc., Natick, MA), a selective dopamine uptake inhibitor (Janowsky et al., 1986). Sections were washed four times for 8 min each in ice-cold buffer at $4^{\circ} \mathrm{C}$. After a quick dip in ice cold distilled water, slides were dried rapidly with a stream of cool air, desiccated overnight, and exposed to Ultrofilm- ${ }^{-3} \mathrm{H}$ (Leica Inc., Malvern, PA) for $30 \mathrm{~d}$.

In situ hybridization histochemistry. The cDNA for preproenkephalin was generously provided by Dr. S. L. Sabol (NIMH). A 970 base pair 

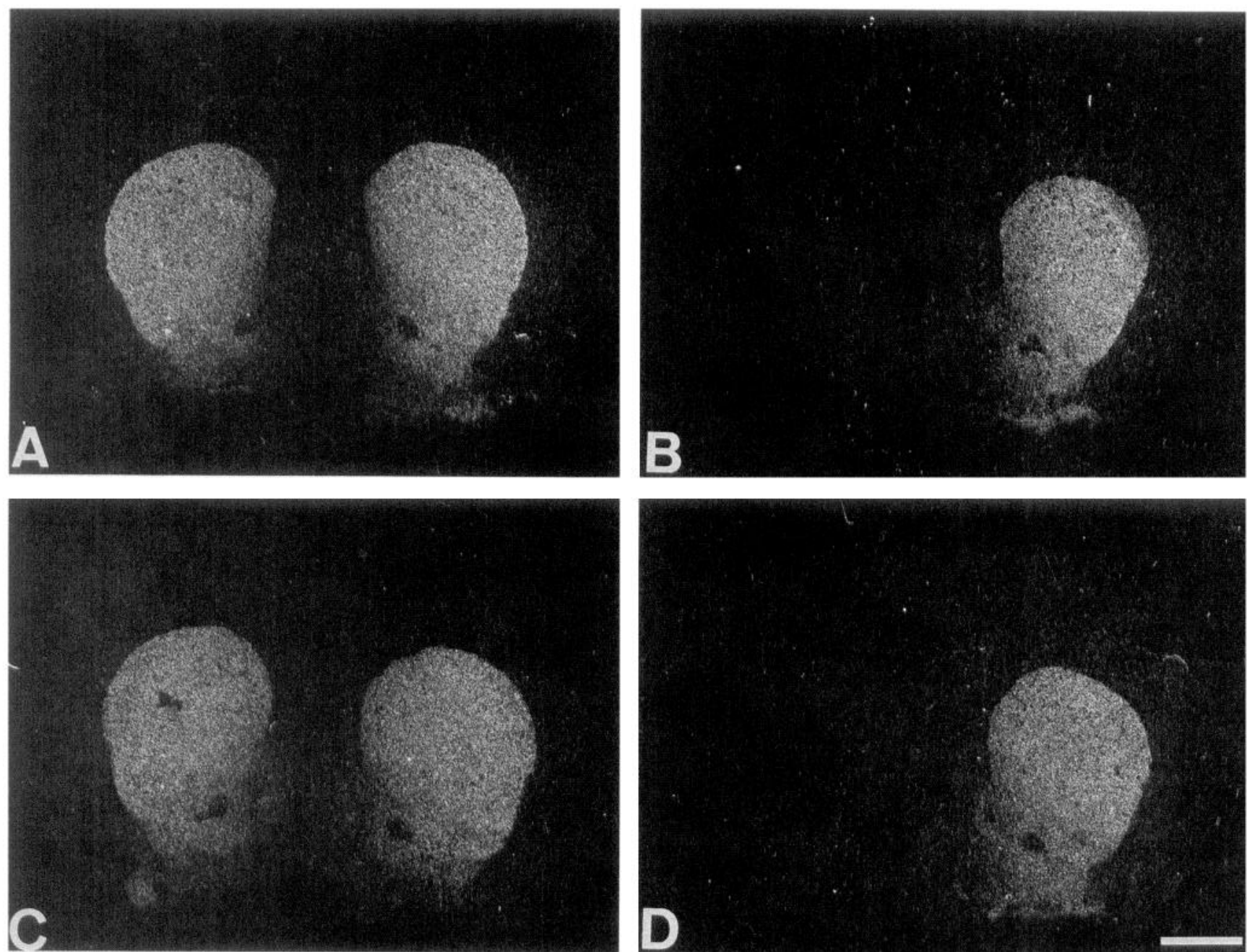

Figure 3. Reverse images of film autoradiograms illustrating the effects of subthalamic nucleus and substantia nigra lesions on ${ }^{3} \mathrm{H}-\mathrm{BTCP}$-labeled dopamine uptake sites in the striatum. Representative striatal sections from control animal $(A)$; rat with a unilateral 6-hydroxydopamine lesion of the substantia nigra $(B)$; rat with a unilateral kainic acid lesion of the subthalamic nucleus $(C)$; and rat with a combination of the two lesions $(D)$. Note that the extent of ${ }^{3} \mathrm{H}-\mathrm{BTCP}$ labeling is similar in $B$ and $D$. Scale bars: $A-D, 2 \mathrm{~mm}$.

\begin{tabular}{|c|c|c|}
\hline Lesion & Ipsilateral & Contralateral \\
\hline CONT & $\begin{array}{r}0.2344 \pm 0.009 \\
(100.0 \pm 3.6 \%)\end{array}$ & $\begin{array}{c}0.2346 \pm 0.011 \\
(100.0 \pm 4.7 \%)\end{array}$ \\
\hline SN & $\begin{aligned} 0.0164 & \pm 0.008^{*} \\
(7.0 & \pm 3.3 \%)\end{aligned}$ & $\begin{array}{r}0.2138 \pm 0.005 \\
(98.8 \pm 2.1 \%)\end{array}$ \\
\hline STN & $\begin{array}{r}0.2235 \pm 0.013 \\
(95.3 \pm 5.5 \%)\end{array}$ & $\begin{aligned} 0.2474 & \pm 0.013 \\
(105.2 & \pm 5.6 \%)\end{aligned}$ \\
\hline SN/STN & $\begin{array}{c}0.0201 \pm 0.005^{*} \\
(8.6 \pm 1.9 \%)\end{array}$ & $\begin{aligned} 0.2350 & \pm 0.007 \\
(100.2 & \pm 3.0 \%)\end{aligned}$ \\
\hline
\end{tabular}

Mean optical density measured from film autoradiograms of rats with sham lesion (CONT), a unilateral lesion of the substantia nigra (SN), a unilatera lesion of the subthalamic nucleus (STN), or a combination of the two lesions (SN/STN). Data are expressed as absolute values \pm SEM of the ipsilateral and contralateral striatum from five rats per group. Numbers in parentheses are percentage of control \pm SEM.

${ }^{*} p<0.05$ when absolute values were compared to the corresponding side of control using ANOVA with Dunnett's post hoc test. transcript from the gene encoding preproenkephalin A was isolated from a rat striatal library and incorporated into the plasmids pSP64 and pSP65 downstream from SP6 promoters oriented in opposite directions (Yoshikawa et al., 1984). This provided the templates for the synthesis of RNA probes which were either "antisense" (complementary to cellular mRNA) or "sense" (identical to cellular mRNA). The cDNA for $\beta$-preprotachykinin (substance P) was kindly provided by Dr. J. E. Krause (Washington University, St. Louis MO). This cDNA consists of a 560 base sequence isolated from a Sprague-Dawley rat striatal library and was incorporated into a pGEM1 vector with SP6 and T7 promoter regions (Krause et al., 1987). The GAD67 cDNA, which consists of a full-length 2.3 kilobase sequence isolated from a cat occipital cortex library and incorporated into the pSP65 (antisense) and pSP64 (sense) vectors (Kaufman et al., 1986; Erlander et al., 1991), was kindly provided by Dr. A.J. Tobin (UCLA, Los Angeles, CA). It showed a 97\% sequence identity with the cloned rat cDNA encoding GAD67 (Erlander et al., 1991). The somatostatin cDNA consists of a 400 base sequence isolated from a rat medullary thyroid carcinoma cDNA library and incorporated into the pSP64 transcription vector. This cDNA, which was a generous gift of Dr. R. H. Goodman (Vollum Institute, Portland, OR), encodes the tetradecapeptide somatostatin and somatostatin 28 in addition to a 51 amino acid $\mathrm{NH}_{2}$ terminal extension (Goodman et al., 1982). The protocol for probe synthesis and in situ hybridization has 


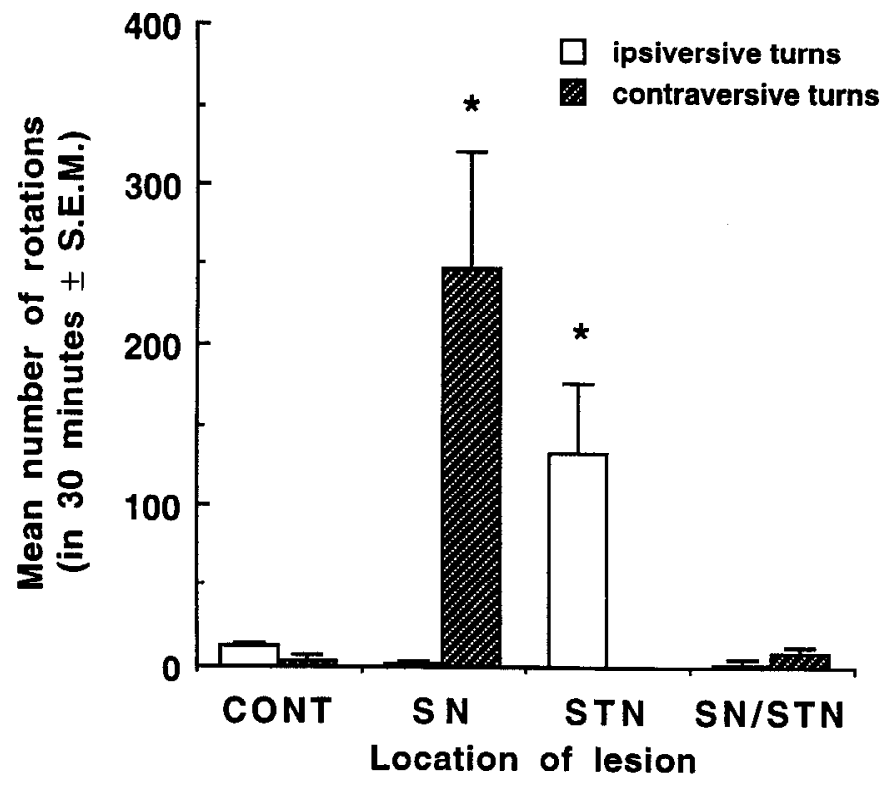

Figure 4. Rotational behavior in lesioned animals following peripheral administration of apomorphine $(0.5 \mathrm{mg} / \mathrm{kg}, \mathrm{s.c}$.). Rats received either a sham lesion (CONT), a unilateral 6-hydroxydopamine lesion of the substantia nigra $(S N)$, a unilateral kainic acid lesion of the subthalamic nucleus $(S T N)$, or a combination of the two lesions (SN/STN). The bars represent the mean number \pm SEM of ipsiversive (towards the lesion, open bars) or contraversive (away from the lesion, hatched bars) rotations in a $30 \mathrm{~min}$ test period. Asterisks indicate statistically significant differences $(p<0.05)$ between absolute values ( $n=5$ /group) compared with ANOVA and Dunnett's post hoc comparison.

been described previously (Chesselet et al., 1987). Briefly, the synthesis mixture consisted of $10 \mu \mathrm{M}$ UTP, $2.5 \mu \mathrm{M}{ }^{35} \mathrm{~S}-\mathrm{UTP}(1000 \mathrm{Ci} / \mathrm{mmol}$, NEN/Du Pont, Boston, MA), ATP, CTP, and GTP in excess, SP6 or T7 RNA polymerase, dithiothreitol (DTT), ribonuclease inhibitor (RNAsin), and $2 \mu \mathrm{g}$ of linearized DNA containing the insert. Due to its large size, the GAD67 RNA probe was partially hydrolyzed into 100-200 base pair fragments for increased tissue penetration (Chesselet et al, 1987). Following the synthesis, the probes were extracted in phenol/ chloroform/isoamyl alcohol and precipitated overnight in ethanol at $-70^{\circ} \mathrm{C}$.

For in situ hybridization histochemistry, experiments were performed on frontal sections $(10 \mu \mathrm{m})$ through the striatum (A-P: $1.7 \mathrm{~mm})$, globus pallidus (A-P: $-0.92 \mathrm{~mm}$ ), and entopeduncular nucleus (A-P: -2.8 $\mathrm{mm}$ ) based on the atlas of Paxinos and Watson (1986). Sections were brought to room temperature from $-70^{\circ} \mathrm{C}$ under a stream of cool air, postfixed in 3\% paraformaldehyde, acetylated, and dehydrated. Sections were incubated with $3-5 \mathrm{ng}$ probe $(400,000 \mathrm{dpm} / \mathrm{ng})$ in humid chambers at $50^{\circ} \mathrm{C}$ for $31 / 2$ hours. Posthybridization treatments included three washes in $50 \%$ formamide, $2 \times \mathrm{SSC}(0.3 \mathrm{M} \mathrm{NaCl} / 0.03 \mathrm{M}$ sodium citrate) at $52^{\circ} \mathrm{C}$ and a $30 \mathrm{~min}$ incubation in $100 \mu \mathrm{g} / \mathrm{ml}$ RNase A (Sigma Chemical Co., St. Louis, MO) at $37^{\circ} \mathrm{C}$. After an overnight rinse in $2 \times$ SSC, $0.05 \%$ Triton $\mathrm{X}-100$, sections were dehydrated in graded ethanols, defatted in xylene, and desiccated. In the striatum, there is a high density of cells expressing the mRNAs of interest, therefore film autoradiography ( ${ }^{3} \mathrm{H}$-Ultrofilm, Leica, Malvern, PA) was used for quantification. In the globus pallidus and entopeduncular nucleus, the neurons expressing GAD67 and somatostatin mRNAs are scattered among myelinated fibers and autoradiographic signals cannot be optimally detected on film (Chesselet et al., 1987). Therefore, sections were coated with Kodak NTB3 emulsion diluted 1:1 with $300 \mathrm{~mm}$ ammonium acetate for single-cell analysis. Test slides or strips of film were developed at regular intervals to determine optimal exposure time, that is, when specific labeling was robust but not saturating based on O.D. standards and previous emulsion experiments. This corresponds to 3-10 d for the pallidum and 14-30 d for the striatum. Both films and emulsion autoradiograms were developed in Kodak D-19 developer and fixed in Kodak Rapid Fix. Emulsion coated sections were lightly counterstained with hematoxylin and eosin and coverslipped with Eukitt mounting media (Calibrated Instruments, IIawthorne, NY).

The anatomical specificity of autoradiographic labeling with each of the probes has been previously characterized and was verified in each individual experiment (Chesselet et al., 1987; Soghomonian and Chesselet, 1991; Salin and Chesselet, 1992). No specific labeling was observed in control sections processed with sense RNA probes.

Quantification. The level of labeling over individual neurons in the globus pallidus and entopeduncular nucleus was measured on emulsioncoated slides with a MORPHON image analysis system (Smolen and Beaston-Wimmer, 1990). This system consists of a MTI 65 video camera, a Leitz microscope, a Numonics GraphicMaster image digitizer and an IBM 212 computer. The anatomical structure of interest was outlined under low-power and the area covered by silver grains over individual labeled neurons was quantified. Neurons were visualized under bright ficld illumination with a $40 \times$ objective and projected onto a video monitor with a resulting magnification of $1200 \times$. Each neuron of interest was outlined using the digitizing tablet and the threshold gray value was adjusted to distinguish grains from background staining. The portion of the enclosed area which was above threshold illumination was determined and expressed as the number of pixels occupied by silver grains. Linear regression analysis has shown a direct correlation $(+0.96$ for $40 \times$ magnification) between the number of pixels measured with the MORPHON system and visual grain counting (Salin et al., 1990; Chesselet and Weiss-Wunder, 1994). For the present experiments, specific labeling was arbitrarily defined as the presence of 10 or more grains per pallidal neuron.

A random sample of 50 neurons per animal was measured in each anatomical structure on the sides ipsilateral and contralateral to the lesion. This was accomplished by moving nonoverlapping frames over the region and measuring neurons with at least 10 grains over the cell body until 50 labeled cells were analyzed. We have previously verified that this sample size provides a very reliable estimate of the average level of labeling in pallidal neurons (J. J Soghomonian and M. F. Chesselet, unpublished observations; see Soghomonian and Chesselet, 1992). In the present experiments, autoradiographic background in areas devoid of labeled cells was extremely low and thus the values were not subtracted. An average level of labeling per neuron was determined for both the ipsilateral and contralateral side of each region for each rat, and this value was used for statistical analysis. In addition, frequency distributions of the level of labeling were constructed for each pallidal segment. The density of labeled neurons in the globus pallidus and entopeduncular nucleus was determined from camera lucida drawings.

For striatal sections from in situ hybridization and receptor autoradiographic studies, regional analysis was performed using the Macintosh-based NIH IMAGE analysis system (version 1.44). Kodak optical density (O.D) standards were used to construct a curve from which O.D. values could be determined from gray levels on the film. Optical density measurements were taken separately for the ipsilateral and contralateral striatum. The results from two sections per rat were averaged and the mean O.D. for the ipsilateral and contralateral striatum was calculated.

Data analysis. Only slides processed concurrently in individual experiments were compared statistically and all statistical analyses were done on absolute values with the STATVIEW 512+ INTERACTIVE STATISTICS AND GRAPHICS PACKAGE (version 1.0, Abacus Concepts). For autoradiography and in situ hybridization data, comparisons were made between the ipsilateral or contralateral side of lesioned rats and the corresponding side of control rats using ANOVA and the Dunnett's post hoc test with $p<0.05$ considered significant (Bruning and Kintz, 1987). Comparisons between the ipsilateral and contralateral sides of animals were made using a paired $t$ test with $p<0.05$ considered significant. For the purpose of comparing parallel experiments graphically, data are expressed as the percentage of the corresponding side of control ( \pm SEM).

\section{Results}

\section{Histological verification of the lesions}

Rats used in these studies were selected on the basis of histological examination of the lesions. The subthalamic nucleus of rats with local injections of kainic acid $(0.5 \mathrm{nmol}$ in $0.1 \mu \mathrm{l})$ showed nearly complete loss of neurons and extensive gliosis in the entire nucleus (Fig. 1 $B, D$ ) compared to controls (Fig. 1A,C), except in a few cases where there was sparing of neurons in the 

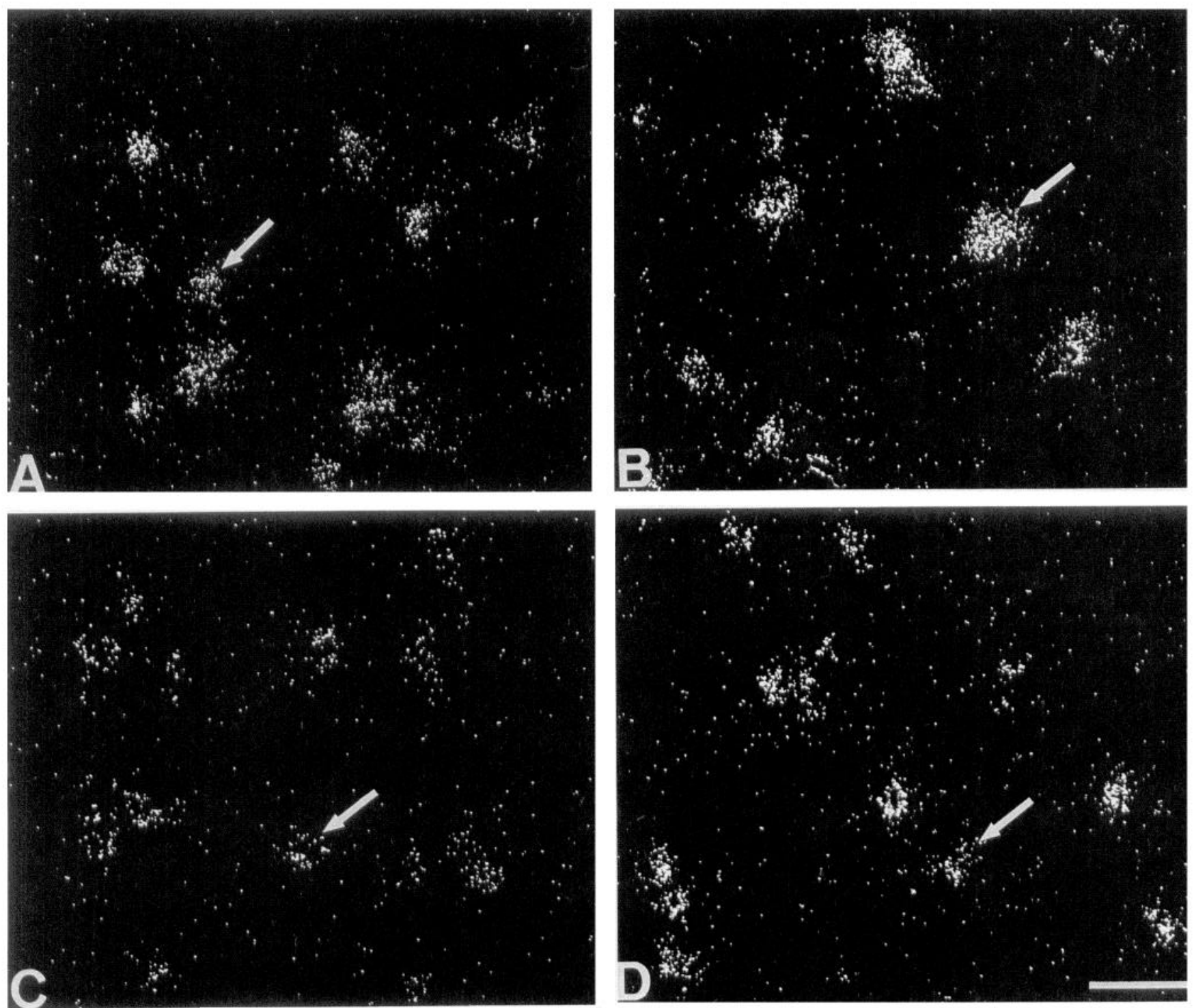

Figure 5. Photomicrographs illustrating the effects of subthalamic nucleus and substantia nigra lesions on the expression of GAD67 mRNA in the globus pallidus ipsilateral to the lesion. Sections of the globus pallidus were processed for in situ hybridization and emulsion autoradiography. Dark-field photomicrographs of neurons (white arrows) labeled with the GAD67 RNA probe in the globus pallidus of rats with sham lesion $(A)$, a unilateral 6-hydroxydopamine (6-OHDA) lesion of the substantia nigra $(B)$, a unilateral kainic acid lesion of the subthalamic nucleus $(C)$, or a combination of the two lesions $(D)$. Note the increase in the number of silver grains over individual neurons in $B$ indicating an increase in GAD67 gene expression in the globus pallidus ipsilateral to a unilateral 6-OHDA lesion the substantia nigra. A decrease in the number of silver grains is observed in $C$ indicating a decrease in GAD67 mRNA levels in the ipsilateral globus pallidus following a unilateral subthalamic nucleus lesion. Scale bars, $50 \mu \mathrm{m}$.

most medial pole of the nucleus. In some cases, gliosis extended into the most ventral part of the zona incerta, although the lesions did not affect the adjacent lateral hypothalamus (Fig. 1B). All animals with 6-hydroxydopamine injections retained for the study showed a profound loss of neuronal cell bodies and gliosis in the substantia nigra pars compacta (Fig. $2 B, D$ ) compared to controls (Fig. $2 A, C$ ). The adjacent substantia nigra pars reticulata was not affected by the lesion (Fig. $2 B$ ). In some animals, there was a moderate loss of neurons in the lateral aspects of the ventral tegmental area adjacent to the substantia nigra (Fig. 2B).

In order to confirm adequate depletion of dopaminergic nerve terminals in nigrostriatal and combined subthalamic-nigrostriatal lesioned animals, autoradiography for the selective dopamine uptake inhibitor ${ }^{3} \mathrm{H}$-BTCP was performed on striatal sections. Loss of ${ }^{3} \mathrm{H}$-BTCP binding sites has been shown to be highly correlated with decreased dopamine level in the striatum after nigrostriatal lesions (Filloux et al., 1988; Vignon et al., 1988). The loss of dopamine uptake sites was greater than $90 \%$ in the striatum ipsilateral to the lesion in rats with either a unilateral lesion of the substantia nigra or a combination of subthalamic nucleus and substantia nigra lesions (Fig. $3 B, D$; Table 1) compared to controls (Fig. 3A). There was no significant difference in the level or topographical distribution of the remaining ${ }^{3} \mathrm{H}$ BTCP sites after single or combined lesions (Fig. 3B,D; Table 1). Unilateral lesions of the subthalamic nucleus had no effect on dopamine uptake sites in the striatum on either side of the brain (Fig. $3 C$, Table 1). 


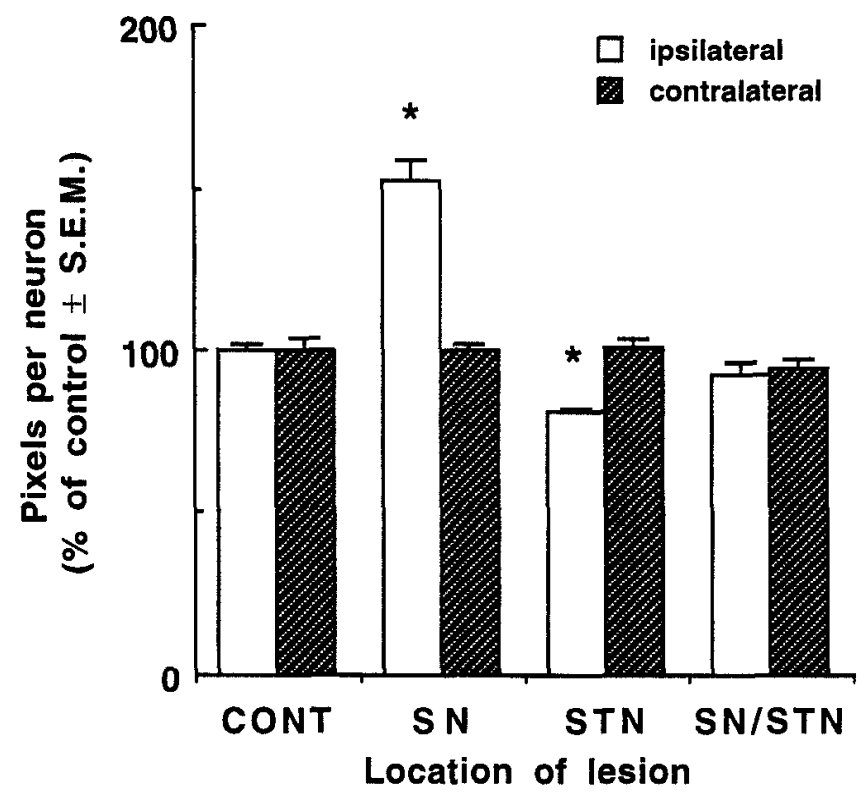

Figure 6. Effect of subthalamic nucleus and substantia nigra lesions on the expression of GAD67 mRNA in the globus pallidus. Rats received either a sham lesion (CONT), a unilateral 6-hydroxydopamine lesion of the substantia nigra $(S N)$, a unilateral kainic acid lesion of the subthalamic nucleus $(S T N)$, or a combination of the two lesions ( $S N$ / $S T N$ ) as described in the Materials and Methods section. Sections of the globus pallidus were processed for in situ hybridization histochemistry and emulsion autoradiography. The bars represent the mean number of pixels occupied by silver grains per neuron on the side ipsilateral (open bars) or contralatcral to the lesion (hatched bars) and are expressed as percent of control \pm SEM. Asterisks indicate statistically significant differences $(p<0.05)$ between absolute values of the corresponding sides of control and lesioned animals ( $n=5$ per group) with ANOVA and Dunnett's post hoc comparison.

\section{Apomorphine-induced rotational behavior}

Rats with a unilateral lesion of the subthalamic nucleus exhibited robust ipsiversive rotational behavior in response to peripheral administration of the dopamine agonist apomorphine $(0.5 \mathrm{mg} /$ $\mathrm{kg}$, s.c.) administered $14 \mathrm{~d}$ postlesion (Fig. 4). The direction of the rotation was opposite to that observed after apomorphine injection in rats with unilateral nigrostriatal lesions. All rats with unilateral nigrostriatal lesions selected for this study displayed robust contraversive circling ( $>200$ turns in $30 \mathrm{~min}$ ) in response to apomorphine given $8 \mathrm{~d}$ after the nigrostriatal lesion (Fig. 4). Rats with combincd lesions did not exhibit any appreciable rotational behavior following injection of apomorphine (Fig. 4). Similarly, control rats which received only stereotaxic injections of saline did not rotate significantly following peripheral administration of apomorphine (Fig. 4). This finding is consistent with the report that subthalamic nucleus ablation markedly reduces dopamine D1 and D2 agonist-induced rotation in rats with a unilateral nigrostriatal lesion (Anderson et al., 1992).

\section{GAD67 gene expression in the globus pallidus (external} pallidum)

Sections from the pallidum were processed for detection of GAD67 mRNA at the single cell level by in situ hybridization histochemistry. Measurements of GAD mRNA in the pallidum, a brain region which contains both GABAergic inpuls and outputs, provides unique information on output neurons. Indeed, both inputs and outputs of the pallidum contain GAD and GABA, whereas only output neurons contain GAD mRNA in this region (Chesselet et al., 1987). Expression of GAD67 mRNA has been correlated with levels or patterns of electrophysiological activity in a number of systems (Chesselet et al., 1993) and has been previously shown to increase in the globus pallidus after unilateral lesions of the nigrostriatal dopaminergic pathway (Kincaid et al., 1992; Soghomonian and Chesselet, 1992). Labeling for GAD67 mRNA in a section of the globus pallidus in a control rat is illustrated in Figure 5A. Unilateral kainic acid lesions of the subthalamic nucleus resulted in a small $(19.2 \%)$ decrease in the level of GAD67 gene expression in the globus pallidus ipsilateral to the lesion (Figs. $5 C, 6$ ). Frequency distribution analysis confirmed this effect by showing a shift to the left of the histogram compared to the ipsilateral side of controls (Fig. 7A,E). The medians of the frequency distributions were also significantly decreased when compared to the corresponding side of control rats (Table 2). The decrease in GAD67 mRNA expression was not due to changes in the number of labeled neurons in the globus pallidus (Table 2).

Confirming previous results (Kincaid et al., 1992; Soghomonian and Chesselet, 1992) unilateral 6-OHDA lesions of the substantia nigra induced a marked increase $(51.9 \%)$ in the level of mRNA encoding GAD67 in the globus pallidus ipsilateral to the lesion (Fig. 5B,6), without changes in the number of labeled neurons (Table 2). The frequency distribution of labeling per cell in the ipsilateral globus pallidus was shifted to the right, and its median increased when compared to the contralateral side and to the ipsilateral side of control rats, confirming the increased level of labeling (Fig. 7A,C,D; Table 2). This increase was abolished in rats with a lesion of the subthalamic nucleus on the same side as the 6-OHDA lesion (Fig. 5D, 6). Analysis of frequency distributions of the level of labeling per neuron confirmed the absence of changes in GAD67 mRNA levels after combined lesions (Fig. 7A,G; Table 2).

\section{$G A D 67$ and somatostatin mRNAs in the entopeduncular nucleus (internal pallidum)}

Subthalamic lesions alone did not significantly change GAD67 mRNA levels in the ipsilateral or contralateral entopeduncular nucleus (Fig. 8). Unilateral 6-OHDA lesions of the substantia nigra, although not causing any significant effects on the side ipsilateral to the lesion, resulted in a significant decrease in GAD67 mRNA levels per neuron and a decrease in the number of labeled neurons in the contralateral entopeduncular nucleus (Fig. 8, Table 2 ), in agreement with previous data from our laboratory (Soghomonian and Chesselet, 1992). Confirming the decrease in GAD67 gene expression, there was a significant decrease in the median of the frequency distribution of the level of labeling and a shift to the left in the histogram compared to controls (Fig. $9 B, D$; Table 2). The contralateral decrease in GAD67 mRNA (Fig. 8 , Table 2) was blocked in rats with lesions of both the subthalamic nucleus and substantia nigra. Analysis of frequency distributions of the level of labeling per neuron confirmed the lack of effects of the combined lesion on GAD67 mRNA levels in the entopeduncular nucleus (Fig. 9B,H; Table 2).

Although somatostatin mRNA is only detected at low levels in a few neurons of the entopeduncular nucleus and adjacent lateral hypothalamus in control rats, nigrostriatal lesions have been previously shown to induce a massive increase in the level of expression of somatostatin mRNA in these regions (Sughomonian and Chesselet, 1991). These findings were confirmed in the present study (Fig. 10). Subthalamic lesions alone had no effect on somatostatin mRNA expression in the ipsilateral en- 

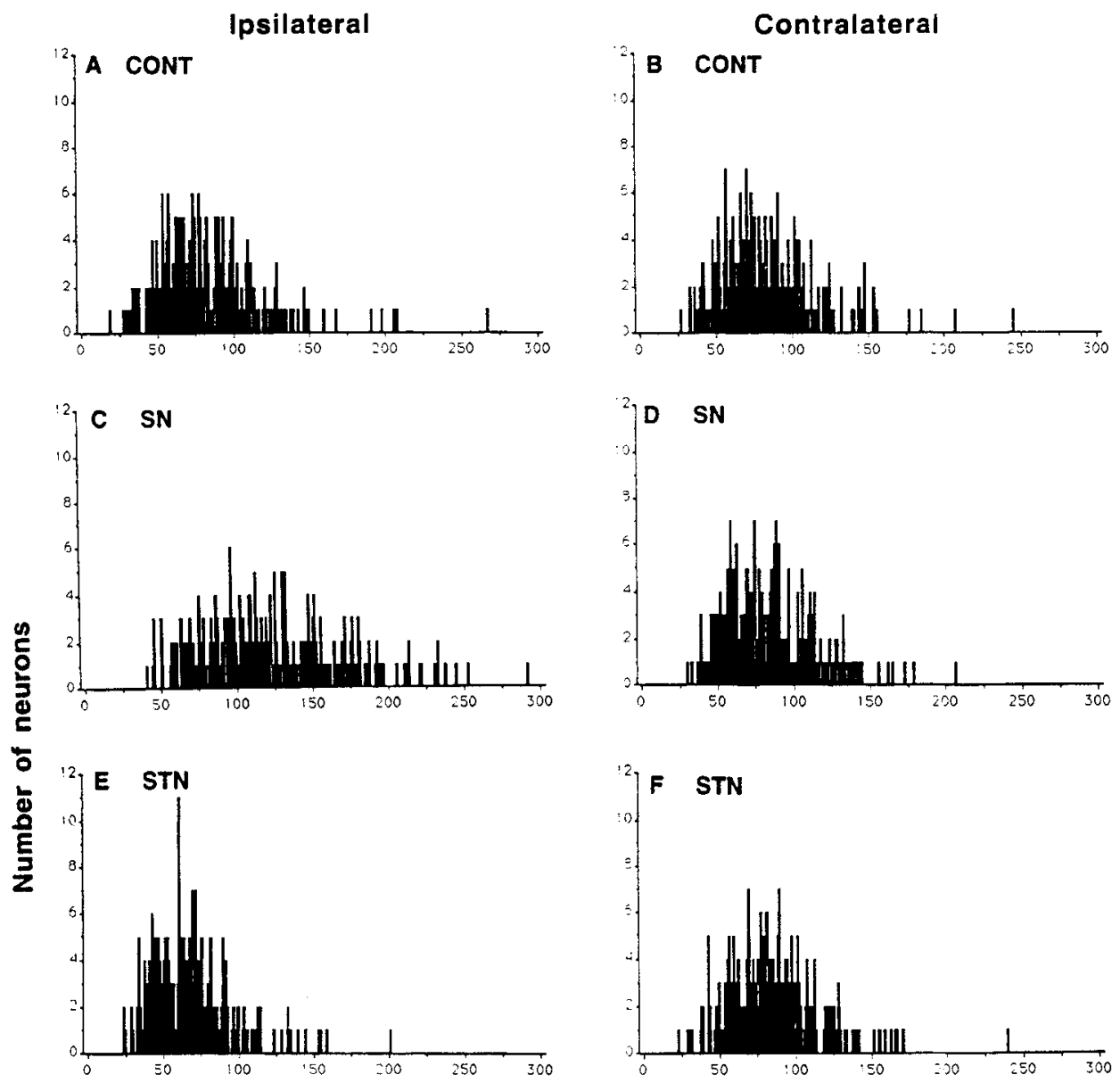

Figure 7. Histograms of frequency distributions of labeling for GAD67 mRNA in the globus pallidus of rats ipsilateral (left panels) or contralateral (right panels) to a sham lesion $(A, B$; $C O N T$ ), a unilateral 6-hydroxydopamine lesion of the substantia nigra $(C$, $D$; $S N$ ), a unilateral kainic acid lesion of the subthalamic nucleus $(E, F ; S T N)$, or a combination of the two lesions $(G$, $H$; $S N / S T N$ ) as described in the Materials and Methods section. Quantification of silver grains over individual neurons was done with the MORPHON image analysis system on sections processed for emulsion autoradiography. Data include values from 50 neurons analyzed per rat ( $n=5 /$ group) from either the ipsilateral or the contralateral globus pallidus. Note the shift to the right in the histogram in $C$ compared to $A$ illustrating an increase in the level of labeling for GAD67 mRNA in the ipsilateral globus pallidus following a unilateral substantia nigra lesion. Also note the shift to the left in the histogram in $E$ compared to $A$ illustrating the decrease in the level of GAD67 gene expression in the globus pallidus following a unilateral subthalamic nucleus lesion. The medians of the frequency distributions are presented in Table 2.

Pixels per neuron

topeduncular nucleus but induced an increase in somatostatin mRNA in the contralateral entopeduncular nucleus (Fig. 10). The contralateral increase in somatostatin mRNA observed following the unilateral subthalamic nucleus lesion was reduced, but not abolished in animals with combined lesions (Fig. 10). In contrast, the ipsilateral increase was no longer significant in aninals with combined lesions (Fig. 10).

\section{Enkephalin and substance $P$ gene expression in the striatum}

In order to assess the effects of the lesions on striatal neurons projecting to the pallidum, the level of mRNAs encoding the neuropeptides enkephalin and substance $P$ were measured in striatal sections with film autoradiography. Enkephalin and substance $P$ are colocalized with GABA in efferent neurons projecting to the globus pallidus and entopeduncular nucleus, respectively (Graybiel, 1990). Lesions of the subthalamic nucleus did not alter the level of enkephalin or substance P mRNA in the striatum (Fig. 11). Confirming previous reports by numerous groups (for review, Graybiel, 1990; Angulo and McEwen, 1994), 6-OHDA lesions of the substantia nigra resulted in a marked increase in enkephalin gene expression in the striatum ipsilateral to the lesion (Fig. 11A). The levels of substance $\mathrm{P}$ mRNA in 6-OHDA lesioned rats were not significantly different from levels in control (saline-injected) rats. However, there was a significant decrease in the ipsilateral striatum when compared compared to the contralateral side of 6-OHDA lesioned rats (Fig. $11 B$ ). Neither the increase in enkephalin nor the decrease in substance $P$ mRNA were observed in the striatum of rats which received both subthalamic nucleus and substantia nigra lesions (Fig. 11).

\section{Discussion}

This study shows that unilateral lesions of the subthalamic nucleus have widespread effects on alterations in gene expression 
Table 2. Medians of the frequency distributions of labeling and number of neurons labeled for GAD67 mRNA after lesions

\begin{tabular}{lcccc} 
& CONT & SN & STN & SN/STN \\
\hline Medians $^{a}$ & & & & \\
$\quad$ Ipsilateral GP & $78.2 \pm 1.6$ & $119.4 \pm 4.2^{*}$ & $62.4 \pm 1.4^{*}$ & $72.1 \pm 3.9$ \\
$\quad$ Contralateral GP & $77.8 \pm 2.6$ & $79.6 \pm 1.8$ & $80.4 \pm 2.1$ & $73.2 \pm 2.2$ \\
Ipsilateral EP & $67.4 \pm 1.8$ & $68.4 \pm 2.8$ & $63.4 \pm 1.6$ & $71.0 \pm 2.8$ \\
$\quad$ Contralateral EP & $65.8 \pm 3.3$ & $52.0 \pm 0.9^{*}$ & $66.0 \pm 1.7$ & $69.8 \pm 1.7$ \\
Number of labeled neurons & & & & \\
$\quad$ Ipsilateral GP & $66.2 \pm 6.8$ & $65.0 \pm 10.2$ & $67.1 \pm 4.2$ & $58.9 \pm 3.7$ \\
$\quad$ Contralateral GP & $63.2 \pm 5.3$ & $64.8 \pm 6.9$ & $68.9 \pm 7.3$ & $60.9 \pm 4.5$ \\
Ipsilateral EP & $21.1 \pm 3.9$ & $24.6 \pm 1.7$ & $18.5 \pm 2.8$ & $21.6 \pm 3.1$ \\
Contralateral EP & $27.4 \pm 7.9$ & $11.7 \pm 2.1^{*}$ & $16.7 \pm 1.6$ & $17.6 \pm 3.2$
\end{tabular}

${ }^{*} p<0.05$ when compared to the corresponding side of control animals using ANOVA and Dunnett's post hoc comparison.

${ }^{a}$ Medians of frequency distributions of labeling for GAD67 mRNA in the globus pallidus (GP) and entopeduncular nucleus (EP) both ipsilateral and contralateral to unilateral lesions of the substantia nigra (SN), subthalamic nucleus (STN), or a combination of the two lesions (SN/STN). Frequency distributions of levels of labeling were constructed for individual animals and their medians were determined. Data are mean \pm SEM of values obtained for five rats per group. Absolute values cannot be compared betwecn the GP and EP becausc sections were processed in separate experiments.

${ }^{b}$ Number of labeled neurons per $\mathrm{mm}^{2}$ were measured using camera lucida drawings.

induced by unilateral lesions of the nigrostriatal pathway. The data suggest that the subthalamic nucleus may contribute in more ways than previously thought to the functional consequences of dopamine depletion in the basal ganglia. In addition,

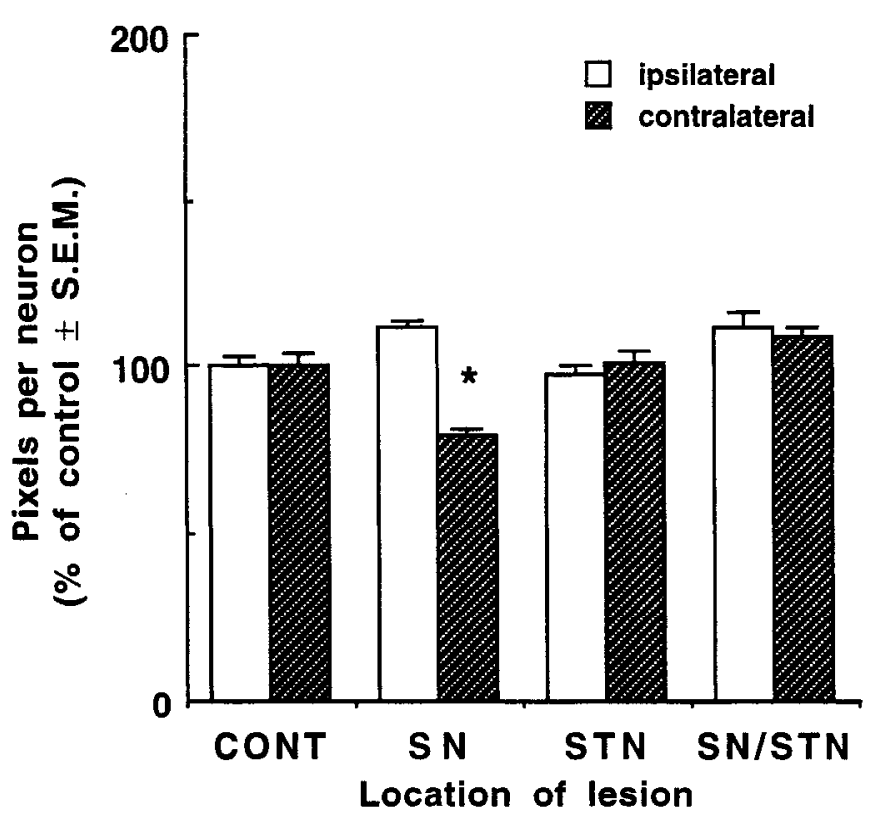

Figure 8. Effect of subthalamic nucleus and substantia nigra lesions on the expression of GAD67 mRNA in the cntopeduncular nucleus. Rats received either a sham lesion $(C O N T)$, a unilateral 6-hydroxydopamine lesion of the substantia nigra $(S N)$, a unilateral kainic acid lesion of the subthalamic nucleus $(S T N)$, or a combination of the two lesions $(S N / S T N)$ as described in the Materials and Methods section. Sections were processed for in situ hybridization histochemistry and emulsion autoradiography. The bars represent the mean number of pixels occupied by silver grains per neuron on the side ipsilateral (open bars) or contralateral to the lesion (hatched bars) and are expressed as percent of control \pm SEM. Asterisks indicate statistically significant differences $(p<0.05)$ between absolute values of the corresponding sides of control and lesioned animals ( $n=5$ per group) with ANOVA and Dunnett's post hoc comparison. the data reveal that unilateral subthalamic lesions in otherwise intact rats produce strong ipsiversive rotational behavior in response to apomorphine but have only restricted effects on the levels of mRNAs examined.

\section{Effects of unilateral subthalamic lesions}

The rotational behavior induced by apomorphine in rats with unilateral lesions of the subthalamic nucleus confirmed previous data (Kafetzopoulos and Papadopoulos, 1983). In the present study, however, the dose and injection volume of kainic acid were fivefold lower to avoid damage to adjacent areas, indicating that the effect was specifically due to the subthalamic nucleus lesion. Peripheral administration of apomorphine increases the firing rate of subthalamic nucleus neurons in intact rats (Thompson and Walters, 1993). After unilateral lesions, this increased activity would only occur in the intact subthalamic nucleus, and the resulting asymmetry could be responsible for the rotational behavior. The motor pathways mediating this effect remain to be determined.

In contrast to unilateral nigrostriatal lesions, lesions of the subthalamic nucleus had minimal effects on gene expression in the basal ganglia. However, the small decrease in GAD67 mRNA levels observed in the ipsilateral globus pallidus is of interest because it suggests that excitatory subthalamic inputs (Parent and Hazrati, 1995) contribute to maintaining levels of GAD67 mRNA in this region. This result is not in contradiction with recent findings of Andrén et al. (1995), who showed increased GAD activity in the globus pallidus after lesion of the subthalamic nucleus in the marmoset. Indeed, the enzyme GAD is present in both afferent terminals and output neurons in the globus pallidus, whereas, GAD mRNA is only present in the cell bodies of output neurons (Chesselet et al., 1987, 1993). The decrease in GAD67 mRNA levels we observed may be related to changes in patterns of firing activity observed in the globus pallidus after lesions of the subthalamic nucleus (Ryan and Sanders, 1993). This adds to previous observations that levels of GAD67 mRNA are correlated with patterns of electrophysi- 
Ipsilateral
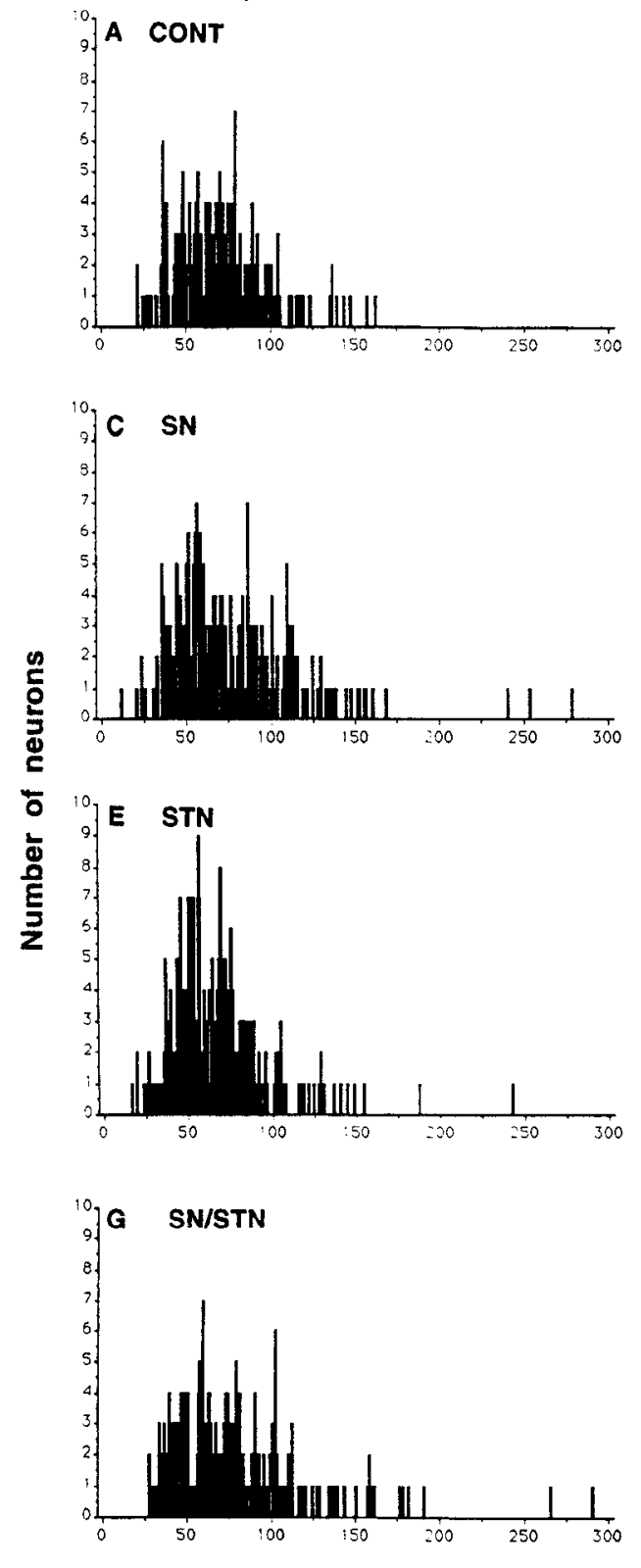
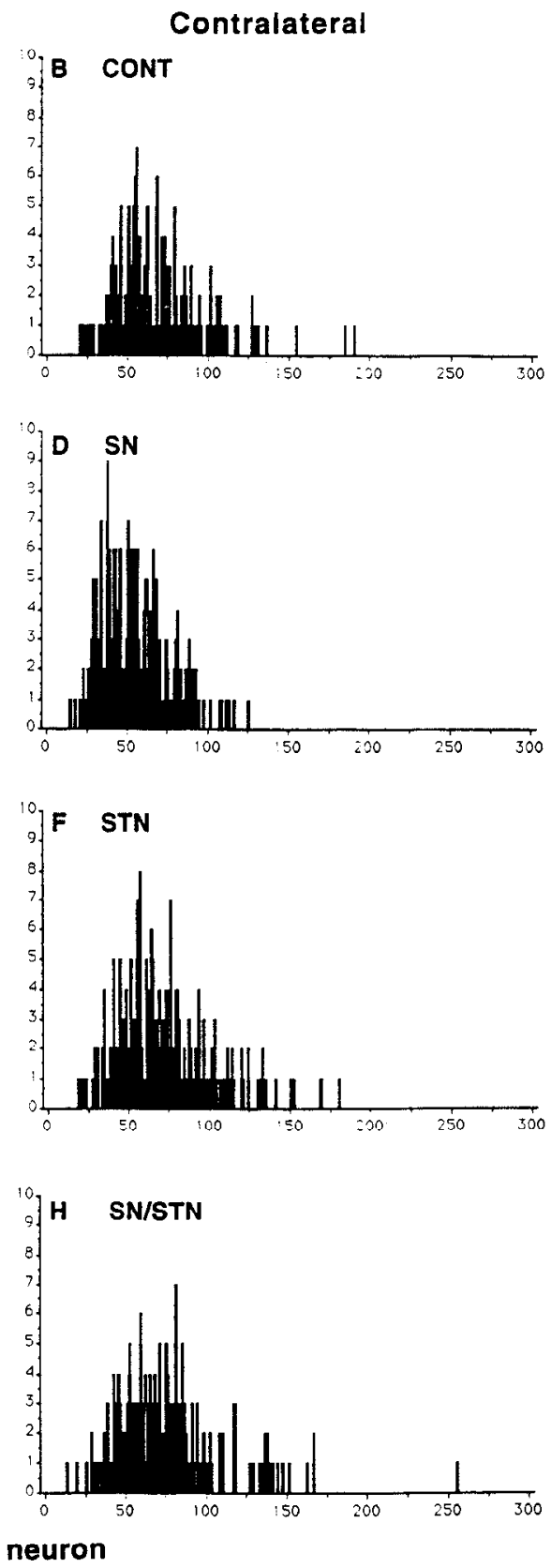

Figure 9. Histograms of frequency distributions of labeling for GAD67 mRNA in the entopeduncular nucleus of rats ipsilateral (left panels) or contralateral (right panels) to a sham lesion $(A, B ; C O N T)$, a unilateral 6-hydroxydopamine lesion of the substantia nigra $(C, D ; S N)$, a unilateral kainic acid lesion of the subthalamic nucleus $(E, F ; S T N)$, or a combination of the two lesions ( $G, F$; SN/STN) as described in the Materials and Methods section. Quantification of silver grains over individual neurons was done with the MORPHON image analysis system on sections processed for emulsion autoradiography. Data include values from 50 neurons analyzed per rat $(n=$ 5 /group) from either the ipsilateral or the contralateral entopeduncular nucleus. Note the shift to the left in the histogram in $D$ compared to $B$ illustrating a decrease in the level of labeling for GAD67 in the contralateral entopeduncular nucleus following a unilateral substantia nigra lesion. The medians of the frequency distributions are presented in Table 2. ological activity in GABAergic neurons (Litwak et al., 1990; Segovia et al., 1990; Drengler and Oltmans, 1993).

Although the subthalamic nucleus also projects to the entopeduncular nucleus (Nauta and Cole, 1978; Kita and Kitai, 1987; Parent and Smith, 1987; Takada et al., 1988; Smith et al., 1990; Berendse and Groenewegen, 1991), no significant changes in GAD67 mRNA were observed in this region after subthalamic lesions. Alterations in the entopeduncular nucleus could occur with a different time course than those in the globus pallidus, as previously observed after pharmacological treatments (Delfs et al., 1995a). However, Blandini and Greenamyre (1995) observed that cytochrome oxidase and succinate dehydrogenase, markers for neuronal activity, were decreased in the ipsilateral globus pallidus but not in the entopeduncular nucleus after unilateral subthalamic lesions. In addition to excitatory inputs from the subthalamic nucleus, the entopeduncular nucleus receives inhibitory inputs from the globus pallidus (Bolam and Smith,
1992). The consequences of subthalamic lesions could be blunted in the entopeduncular nucleus because of this anatomical organization.

\section{Effects of subthalamic lesions in rats with unilateral nigrostriatal lesions}

All previously observed effects of 6-OHDA lesions on the parameters examined (Graybiel, 1990; Soghomonian and Chesselet, 1991, 1992; Angulo and McEwen, 1994) were confirmed in this study, and all these effects were abolished in rats with combined nigrostriatal and subthalamic nucleus lesions. It is unlikely that failure to observe the effects produced by the 6-OHDA lesion alone in animals with combined lesions is due to differences in the location or extent of nigrostriatal lesions between the two groups. Indeed, the histology of the lesions and the level of depletion of dopaminergic terminals were similar in rats with and without subthalamic esions. Furthermore, rats with the com- 


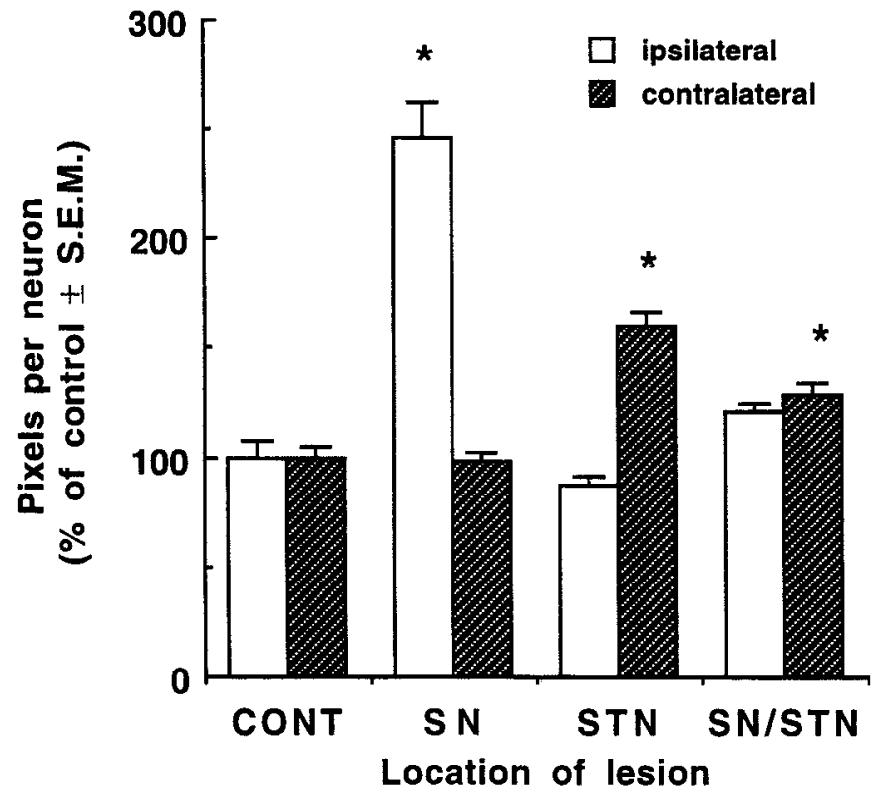

Figure 10. Effect of subthalamic nucleus and substantia nigra lesions on the expression of somatostatin mRNA in the entopeduncular nucleus. Rats received either a sham lesion $(C O N T)$, a unilateral 6-hydroxydopamine lesion of the substantia nigra $(S N)$, a unilateral kainic acid lesion of the subthalamic nucleus $(S T N)$, or a combination of the two lesions $(S N / S T N)$ as described in the Materials and Methods section. Sections were processed for in situ hybridization histochemistry and emulsion autoradiography. The bars represent the mean number of pixels occupied by silver grains per neuron on the side ipsilateral (open bars) or contralateral to the lesion (hatched bars) and are expressed as percent of control \pm SEM. Asterisks indicate statistically significant differences $(p<0.05)$ between absolute values of the corresponding sides of control and lesioned animals ( $n=5$ per group) with ANOVA and Dunnett's post hoc comparison.

bined lesions showed no rotational behavior, whereas rats with subthalamic nucleus lesions alone exhibited strong ipsiversive rotations. Thus, a nigrostriatal lesion sufficient to counteract the rotational behavior resulting from the subthalamic lesion was present in each rat with combined lesions.

Both spontaneous activity and burst firing increase in the subthalamic nucleus after dopamine depletion (Féger et al., 1991; Robledo and Féger, 1991; Hollerman and Grace, 1992; Bergman et al., 1994). Furthermore, NMDA receptors are down-regulated in the globus pallidus after 6-OHDA lesions suggesting an overactive glutamatergic input, most likely from the subthalamic nucleus (Porter et al., 1994). The absence of changes in GAD67 mRNA in the globus pallidus after combined lesions suggests that increased neuronal activity in the subthalamic nucleus triggers the increase in GAD67 mRNA levels observed after unilateral nigrostriatal lesions (Kincaid et al., 1992; Soghomonian and Chesselet, 1992). It has been proposed that increased firing in the subthalamic nucleus after dopamine depletion results from decreased inhibition by afferents from the globus pallidus (Albin et al., 1989; Robledo and Féger, 1991; Bergman et al., 1994). This is unlikely, however, in view of evidence of increased burst firing activity and GAD mRNA expression in the globus pallidus. A reduced stimulation of dopamine receptors by endogenous dopamine normally present in collaterals of the nigrostriatal pathway (Björklund and Lindvall, 1984; Parry et al., 1994) could instead trigger the increased activity of subthalamic neurons (Campbell et al., 1985; Flores et al., 1993).

The present results confirm the complex alterations in GAD67 and somatostatin mRNAs previously observed in the entopeduncular nucleus after unilateral nigrostriatal lesions (Soghomonian and Chesselet, 1991, 1992). Blockade of the ipsilateral increase in somatostatin mRNA in the entopeduncular nuclcus after combined lesions suggests that this effect may be mediated by increased activity in output neurons from the subthalamic nucleus as well. Evidence that unilateral subthalamic lesions also blocked contralateral effects of dopaminergic lesions is not surprising in view of recent evidence that subthalamic lesions in the marmoset induce bilateral changes in a variety of neurotransmitter-related enzymes in the basal ganglia (Andrén et al., 1995). Unilateral dopamine depletion or pharmacological manipulations of the substantia nigra have also been shown to induce contralateral effects on neurotransmitters and metabolism in basal ganglia (Cheramy et al., 1981; Savaki et al., 1984; Zetterström et al., 1986; Normand et al., 1988; Robinson and Whishaw, 1988; Lindefors and Ungerstedt, 1990; Savaki et al., 1992). In addition, we have recently observed that unilateral nigrostriatal lesions induce a bilateral increase in GAD67 mRNA in the reticular thalamic nucleus (Delfs et al., 1995b). The neuronal pathways mediating the decrease in GAD67 mRNA in the contralateral entopeduncular nucleus after 6-OHDA lesions, however, remain ill defined (Soghomonian and Chesselet, 1992). Because changes in basal ganglia output resulting from dopamine depletion ultimately affect cortical neurons, it is possible that contralateral effects of unilateral dopaminergic lesions are mediated by bilateral corticostriatal projections (McGeorge and Faull, 1989).

Recent data suggest that corticostriatal pathways may also be important for the effects of dopamine depletion in the striatum. Electrophysiological and binding studies provide indirect evidence for increased release of glutamate from corticostriatal neurons in the striatum of dopamine-denervated rats (Calabresi et al., 1993; Wüllner et al., 1994). Furthermore, Campbell and Björklund (1994) have shown that knife-cut transections of the cerebral cortex prevent enkephalin mRNA increases in the striatum of rats with unilateral nigrostriatal lesions. A contribution of the corticostriatal pathways may explain why changes in enkephalin and substance $P$ mRNA levels in the striatum were blocked in animals with combined lesions. Indeed, it is unlikely that this effect was due to the lesion of neurons projecting from the subthalamic nucleus to the striatum because this pathway is sparse and restricted to the rostroventral striatum (Kita and Kitai, 1987), whereas changes in enkephalin and substance P mRNAs were ohserved in the entire dorsal striatum. Similarly, these effects are probably not mediated by projections from the globus pallidus because blockade of haloperidol-induced increases in GAD67 mRNA in the globus pallidus by scopolamine does not abolish enkephalin increases in the striatum (Delfs et al., 1995a). Stimulation of dopamine receptors in the striatum modulates neuronal responses to glutamate, the neurotransmitter of corticostriatal neurons (Cepeda et al., 1993). Therefore, direct loss of stimulation of striatal dopamine receptors and changes in activity of corticostriatal neurons indirectly mediated by the subthalamic nucleus may concur to induce changes in striatal gene expression after nigrostriatal lesions.

In conclusion, the results lead one to reconsider the relative contribution of dopamine depletion within the striatum, and of polysynaptic pathways activated by the subthalamic nucleus, to the molecular effects observed after dopamine depletion. The pivotal role of the subthalamic nucleus may explain the striking beneficial effects of lesioning subthalamic neurons or antago- 


\section{A ENKEPHALIN mRNA}

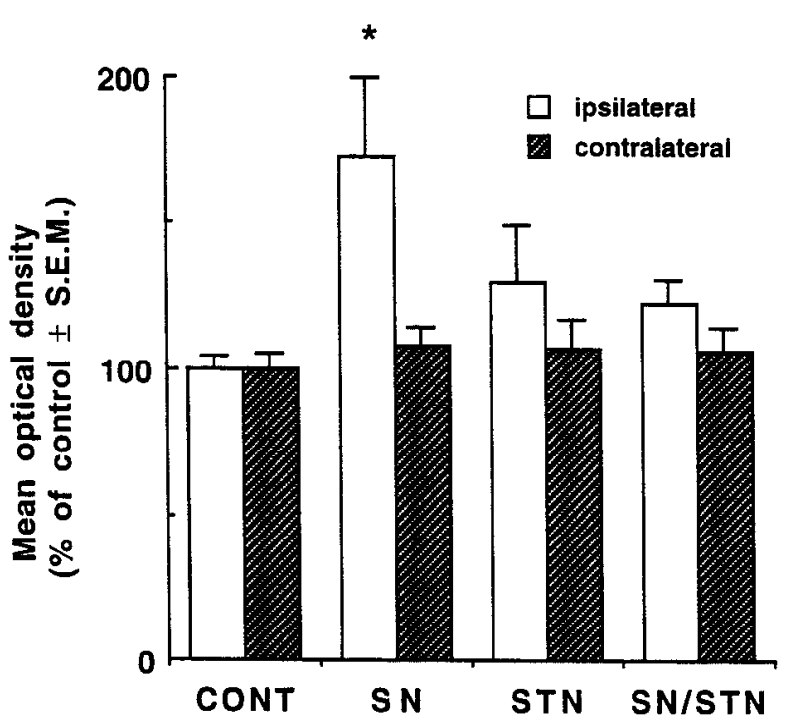

\section{B SUBSTANCE P mRNA}

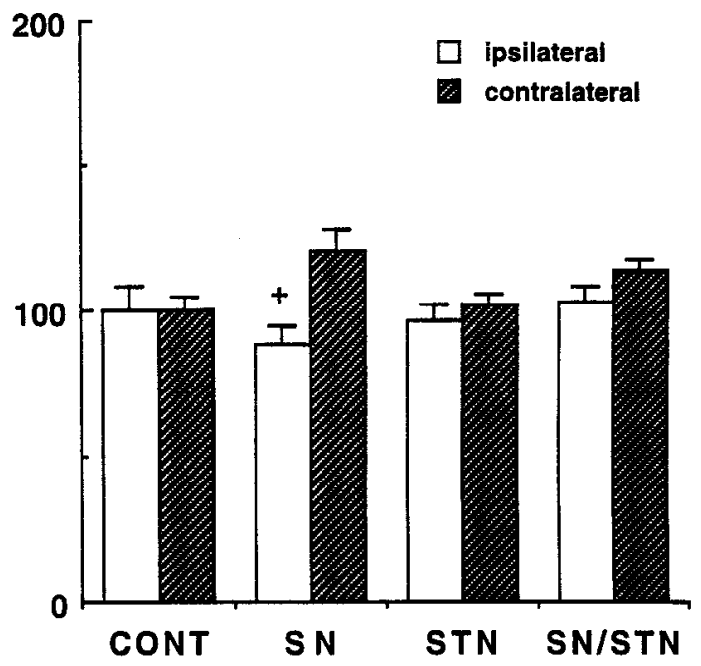

Figure 11. Effect of subthalamic nucleus and substantia nigra lesions on the expression of enkephalin $(A)$ and substance P mRNA $(B)$ in the striatum. Rats received either a sham lesion (CONT), a unilateral 6-hydroxydopamine lesion of the substantia nigra $(S N)$, a unilateral kainic acid lesion of the subthalamic nucleus (STN), or a combination of the two lesions (SN/STN) as described in the Materials and Methods section. Sections were processed for in situ hybridization histochemistry and film autoradiography. The bars represent the mean optical density measured from film autoradiograms on the side ipsilateral to the lesion (open bars) or contralateral to the lesion (hatched bars) and are expressed as percent of control \pm SEM. Asterisks indicate statistically significant differences $(p<0.05)$ between absolute values of the corresponding sides of control and lesioned animals $(n=5$ per group) with ANOVA and Dunnett's post hoc comparison. Plus sign $(+)$ indicates a statistically significant difference $(p<0.05)$ between the ipsilateral and contralateral side using a paired $t$ test.

nizing their effects on symptoms resulting from dopamine depletion in animal models and patients with Parkinson's disease (Bergman et al., 1990; Aziz et al., 1991; Brotchie et al., 1991; Klockgether et al., 1991; Greenamyre et al., 1994; Limousin et al., 1995). Accordingly, pharmacological approaches targeted to the subthalamic nucleus itself may also open new possibilities for the treatment of neurodegenerative diseases of the basal ganglia.

\section{References}

Albin RL, Young AB, Penney JB (1989) The functional anatomy of basal ganglia disorders. Trends Neurosci 12:366-375.

Anderson JJ, Chase TN, Engber TM (1992) Differential effect of subthalamic nucleus ablation on dopamine D1 and D2 agonist-induced rotation in 6-hydroxydopamine-lesioned rats. Brain Res 588:307310.

Andrén PE, Levin ED, Liminga U, Gunne L (1995) Behavioral and neurochemical consequences of ibotenic acid lesion in the subthalamic nucleus of the common marmoset. Brain Res Bull 36:301-307.

Angulo JA, McEwen BS (1994) Molecular aspects of neuropeptide regulation and function in the corpus striatum and nucleus accumbens. Brain Res Rev 19:1-28.

Aziz TZ, Peggs D, Sambrook MA, Crossman AR (1991) Lesion of the subthalamic nucleus for the alleviation of 1-methyl-4-phenyl-1,2,3,6tetrahydropyridince (MPTP)-induced parkinsonism in the primate. Mov Disord 6:288-292.

Benazzouz A, Gross C, Féger J, Boraud T, Bioulac B (1993) Reversal of rigidity and improvement in motor performance by subthalamic high-frequency stimulation in MPTP-treated monkeys. Eur J Neurosci 5:382-389.

Berendse HW, Groenewegen HJ (1991) The connections of the medial part of the subthalamic nucleus in the rat: evidence for a parallel organization. Adv Behav Biol 39:89-98.

Bergman H, Wichmann T, DeLong MR (1990) Reversal of experimental parkinsonism by lesions of the subthalamic nucleus. Science 249: 1436-1438.

Bergman H, Wichmann T, Karmon B, DeLong MR (1994) The primate subthalamic nucleus. II. Neuronal activity in the MPTP model of parkinsonism. J Neurophysiol 72:507-520.

Björklund A. Lindvall O (1984) Dopamine-containing systems in the CNS. In: Handbook of clinical neuroanatomy, Vol 3 (Björklund A, Hökfelt T, eds), pp 55-122. Amsterdam: Elsevier

Blandini F, Greenamyre JT (1995) Effect of subthalamic nucleus lesion on mitochondrial enzyme activity in rat basal ganglia. Brain Res 669: $59-66$.

Bolam JP, Smith Y (1992) The striatum and globus pallidus send convergent synaptic inputs onto single cells in the entopeduncular nucleus of the rat: a double anterograde labelling study combined with postembedding immunocytochemistry for GABA. J Comp Neurol 321:456-476.

Brotchie JM, Mitchell IJ, Sambrook MA, Crossman AR (1991) Alleviation of parkinsonism by antagonism of excitatory amino acid transmission in the medial segment of the globus pallidus in rat and primate. Mov Disord 6:133-138.

Bruning JL, Kintz BL (1987) Computational handbook of statistics, 3rd edition. Glenview, IL: Scott, Foresman.

Calabresi P, Mercuri NB, Sancesario G, Bernardi G (1993) Electrophysiology of dopamine-denervated striatal neurons. Brain 116:433452.

Campbell K, Björklund AJ (1994) Prefrontal corticostriatal afferents maintain increased enkephalin gene expression in the dopamine-denervated rat striatum. Eur J Neurosci 6:1371-1383.

Campbell GA, Eckhardt MJ, Weight FF (1985) Dopaminergic mechanisms in subthalamic nucleus of rat: analysis using horseradish peroxidase and microiontophoresis. Brain Res 333:261-270.

Cepeda C, Buchwald NA, Levine MS (1993) Neuromodulatory actions of dopamine in the neostriatum are dependent upon the excitatory amino acid receptor subtypes activated. Proc Natl Acad Sci USA 90: 9576-9580.

Cheramy A, Leviel V, Daudet F, Guibert B, Chesselet MF, Glowinski J (1981) Involvement of the thalamus in the reciprocal regulation of the two nigrostriatal pathways. Neuroscience 6:2657-2668.

Chesselet MF, Weiss-Wunder LT (1994) Quantification of in situ hybridization histochemistry. In: In situ hybridization in neurobiology, advances in methodology (Eberwine JH, Valentino KL, Barchas JD, eds), pp 114-123. New York: Oxford UP. 
Chesselet MF, Weiss L, Wuenschell C, Tobin AJ, Affolter HU (1987) Comparative distribution of mRNAs for glutamic acid decarboxylase, tyrosine hydroxylase, and tachykinins in the basal ganglia: an in situ hybridization study in rodent brain. J Comp Neurol 262:125-140.

Chesselet MF, Mercugliano M, Soghomonian JJ, Salin P, Qin Y, Gonzales C (1993) Regulation of glutamic acid decarboxylase gene expression in efferent neurons of the basal ganglia. Prog Brain Res 99: 143-154.

Delfs JM, Anegawa NJ, Chesselet MF (1995a) Glutamic acid decarboxylase mRNA in rat pallidum: comparison of the effects of haloperidol, clozapine and combined haloperidol-scopolamine treatments. Neuroscience 66:67-80.

Delfs JM, Soghomonian JJ, Ciaramitaro VM, Chesselet MF (1995h) Unilateral 6-hydroxydopamine (6-OHDA) lesions of the substantia nigra induce bilateral increases in glutamic acid decarboxylase (GAD) mRNA in the reticular thalamic nucleus. Soc Neurosci Abstr 21: in press.

DeLong MR (1990) Primate models of movement disorders of basal ganglia origin. Trends Neurosci 13:281-285.

Deniau JM, Hammond C, Chevalier G, Féger J (1978) Evidence for branched subthalamic nucleus projections to substantia nigra, entopeduncular nucleus and globus pallidus. Neurosci Lett 9:117-121.

Drengler SM, Oltmans GA (1993) Rapid increases in cerebellar Purkinje cell glutamic acid decarboxylase (GAD 67) mRNA after lesioninduced increases in cell firing. Brain Res 615:175-179.

Erlander MG, Tillakaratne NJ, Feldblum S, Patel N, Tobin AJ (1991) Two genes encode distinct glutamic acid decarboxylases. Neuron 7:91-100.

Féger J, Robledo P, Renwart N (1991) The subthalamic nucleus: new data, new questions. Adv Behav Biol 39:99-108.

Filion M (1979) Effects of interruptions of the nigrostriatal pathway and of dopaminergic agents on the spontaneous activity of globus pallidus neurons in the awake monkey. Brain Res 178:425-441.

Filion M, Tremblay L (1991) Abnormal spontaneous activity of globus pallidus neurons in monkeys with MPTP-induced parkinsonism. Brain Res 547:142-151.

Filloux F, Hunt MA, Wamsley JK (1989) Localization of the dopamine uptake complex using [ $\left.{ }^{3} \mathrm{H}\right] \mathrm{N}-[1-(2-$ benzo(b)thiophenyl)cyclohexyl]piperidine $\left.\left({ }^{3} \mathrm{H}\right] \mathrm{BTCP}\right)$ in rat brain. Neurosci Lett 100:105-110.

Flores G, Valencia J, Rosales MG, Sierra A, Aceves J (1993) Appearance of EMG activity and motor asymmetry after unilateral lesions of the dopaminergic innervation to the subthalamic nucleus in the rat. Neurosci Lett 162:153-156.

Goodman RH, Jacobs JW, Dee PC, Habener JF (1982) Somatostatin 28 encoded in a cloned cDNA obtained from a rat medullary thyroid carcinoma. J Biol Chem 257:1156-1159.

Graybiel AM (1990) Neurotransmitters and neuromodulators in the basal ganglia. Trends Neurosci 13:244-253.

Greenamyre JT, Eller RV, Zhang 7, Ovadia A, Kurlan R, Gash DM (1994) Antiparkinsonian effects of ramacemide hydrochloride, a glutamate antagonist, in rodent and primate models of Parkinson's disease. Ann Neurol 35:655-661.

Herrero MT, Ruberg M, Hirsch EC, Guridi J, Luquin MR, Guillen J, Javoy-Agid F, Agid Y, Obeso JA (1993) Changes in GAD mRNA expression in neurons of the internal pallidum in parkinsonian monkeys after L-DOPA therapy. Soc Neurosci Abstr 19:132.

Hollerman JR, Grace AA (1992) Subthalamic nucleus cell firing in the 6-OHDA-treated rat: basal activity and response to haloperidol. Brain Res 590:291-299.

Hudson JL, van Horne CG, Strömberg I, Brock S, Clayton J, Masserano J, Hoffer BJ, Gerhardt GA (1993) Correlation of apomorphine- and amphetamine-induced turning with nigrostriatal dopamine content in unilateral 6 hydroxydopamine lesioned rats. Brain Res 626:167-174.

Janowsky A, Berger P, Vocci F, Labarca R, Skolnick P and Paul SM (1986) Characterization of sodium-dependent $\left[{ }^{3} \mathrm{H}\right] \mathrm{GBR} 12935$ binding in brain: a radioligand for selective labeling of the dopanine transport complex. J Neurochem 46:1272-1276.

Kafetzopoulos E, Papadopoulos G (1983) Turning behavior after unilateral lesion of the subthalamic nucleus in the rat. Behav Brain Res $8: 217-223$.

Kaufman DL, McGinnis JF, Krieger NR, Tobin AJ (1986) Brain glutamate decarboxylase cloned in lambda gt11: fusion protein produces gamma-aminobutyric acid. Science 232:1138-1140.

Kincaid AE, Albin RL, Newman SW, Penney JB, Young AB (1992) 6-hydroxydopamine lesions of the nigrostriatal pathway alter the ex- pression of glutamate decarboxylase messenger RNA in rat globus pallidus projection neurons. Neuroscience 51:705-718.

Kita H, Kitai ST (1987) Efferent projections of the subthalamic nucleus in the rat: light and electron microscopic analysis with the PHA-L method. J Comp Neurol 260:435-452.

Kitai ST, Kita H (1987) Anatomy and physiology of the subthalamic nucleus: a driving force of the basal ganglia. Adv Behav Biol 32: $357-373$.

Klockgether T, Turski L, Honore T, Zhang Z, Gash DM, Kurlan R, Greenamyre JT (1991) The AMPA receptor antagonist NBQX has antiparkinsonian effects in monoamine-depleted rats and MPTP-treated monkeys. Ann Neurol 30:717-723.

Krause JF, Chirgwin IM, Carter MS, Xu 7.S, Hershey AD (1987) Three rat preprotachykinin mRNAs encode the neuropeptides substance $P$ and neurokinin A. Proc Natl Acad Sci USA 84:881-885.

Limousin P, Pollak P, Bennazouz A, Hoffman D, LeBas JF, Broussolle E, Perret JE, Benabid AL (1995) Effect of parkinsonian signs and symptoms of bilateral subthalamic nucleus stimulation. Lancet 345 : 91-95.

Lindefors N, Ungerstedt $\mathbf{U}$ (1990) Bilateral regulation of glutamate tissue and extracellular levels in the caudate-putamen by midbrain dopamine neurons. Neurosci Lett 115:248-252.

Litwak J, Mercugliano M, Chesselet MF, Oltmans GA (1990) Increased glutamic acid decarboxylase (GAD) mRNA and GAD activity in cerebellar Purkinje cells following lesion-induced increases in cell firing. Neurosci Lett 116:179-183.

McGeorge AJ, Faull RLM (1989) The organization of the projection from the cerebral cortex to the striatum in the rat. Neuroscience 29 : 503-537.

Miller WC, DeLong MR (1987) Altered tonic activity of neurons in the globus pallidus and subthalamic nucleus in the primate MPTP model of parkinsonism. Adv Behav Biol 32:415-427.

Nauta HJW, Cole M (1978) Efferent projections of the subthalamic nucleus: an autoradiographic study in the monkey and cat. J Comp Neurol 180:1-16.

Normand E, Popovici T, Onteniente B, Fellmann D, Piatier-Tonneau D, Auffray C, Bloch B (1988) Dopaminergic neurons of the substantia nigra modulate preproenkephalin A gene expression in rat striatal neurons. Brain Res 439:39-46.

Pan HS, Walters JR (1988) Unilateral lesion of the nigrostriatal pathway decreases the firing rate and alters the firing pattern of globus pallidus neurons in the rat. Synapse 2:650-656.

Parent A, Hazrati L (1995) Functional anatomy of the basal ganglia. II. The place of the subthalamic nucleus and external pallidum in basal ganglia circuitry. Brain Res Rev 20:128-154.

Parent A, Smith Y (1987) Organization of the efferent projections of the subthalamic nucleus in the squirrel monkey as revealed by retrograde labeling methods. Brain Res 436:296-310.

Parry TJ, Fherle-Wang K, Lucki I, Chesselet MF (1994) Dopaminergic stimulation of the subthalamic nucleus elicits oral dyskinesia in rats. Exp Neurol 128:181-190.

Paxinos G, Watson C (1986) The rat brain in stereotaxic coordinates, 2nd edition. San Diego: Academic.

Porter RHP, Greene JG, Higgins DS, Greenamyre JT (1994) Polysynaptic regulation of glutamate receptors and mitochondrial enzyme activities in the basal ganglia of rats with unilateral dopamine depletion. J Neurosci 14:7192-7199.

Rinvik E, Ottersen OP (1993) Terminals of subthalamonigral fibers are enriched with glutamate-like immunoreactivity: an electron microscopic, immunogold analysis in the cat. J Chem Neuroanat 6:19-30.

Robinson TE, Whishaw IQ (1988) Normalization of extracellular dopamine in striatum following recovery from partial unilateral 6-OHDA lesion of the substantia nigra: a microdialysis study in freely moving rats. Brain Res 450:209-224.

Robledo P, Féger J (1991) Acute monoaminergic depletion in the rat potentiates the excitatory effect of the subthalanic nucleus in the substantia nigra pars reticulata but not in the pallidal complex. $\mathbf{J}$ Neural Trans 86:115-126.

Ryan LJ, Sanders DJ (1993) Subthalamic nucleus lesion regularizes firing patterns in globus pallidus and substantia nigra pars reticulata neurons in rats. Brain Res 626:327-331.

Salin P, Chesselet MF (1992) Paradoxical increase in striatal neuropeptide gene expression following ischemic lesions of the cerebral cortex. Proc Natl Acad Sci USA 89:9954-9958.

Salin P, Mercugliano M, Chesselet MF (1990) Differential effects of 
chronic treatment with haloperidol and clozapine on the level of preprosomatostatin mRNA in the striatum, nucleus accumbens, and frontal cortex of rat. Cell Mol Neurobiol 10:127-144.

Savaki HE, Girault JA, Desban M, Glowinski J, Besson MJ (1984) Effects of nigral stimulation following ventromedial thalamic lesions. I. Extrapyramidal system. Brain Res Bull 12:603-616.

Savaki HE, Raos VC, Dermon CR (1992) Bilateral cerebral metabolic effects of pharmacological manipulation of the substantia nigra in the rat: unilateral intranigral application of the inhibitory GABAa receptor agonist muscimol. Neuroscience 50:781-794.

Segovia J, Tillakaratne NJK, Whelan K, Tobin AJ, Gale K (1990) Parallel increases in striatal glutamic acid decarboxylase activity and mRNA levels in rats with lesions of the nigrostriatal pathway. Brain Res 529:345-348.

Smith Y, Parent A (1988) Neurons of the subthalamic nucleus in primates display glutamate but not GABA immunoreactivity. Brain Res 453:353-356.

Smith Y, Hazrati LN, Parent A (1990) Efferent projections of subthalamic nucleus in the squirrel monkey, as studied by the PHA-L anterograde tracing method. J Comp Neurol 294:306-323.

Smolen AJ, Beaston-Wimmer P (1990) Quantitative analysis of in situ hybridization using image analysis. In: In situ hybridization histochemistry (Chesselet MF, ed), pp 175-188. Boca Raton, FL: CRC.

Soghomonian JJ, Chesselet MF (1991) Lesions of the dopaminergic nigrostriatal pathway alter preprosomatostatin messenger RNA levels in the striatum, the entopeduncular nucleus and the lateral hypothalamus of the rat. Neuroscience 42:49 59 .

Soghomonian JJ, Chesselet MF (1992) Effects of nigrostriatal lesions on the levels of messenger RNAs encoding two isoforms of glutamate decarboxylase in the globus pallidus and entopeduncular nucleus of the rat. Synapse 11:124-133.
Soghomonian JJ, Pedneault S, Audet G, Parent A (1994) Increased glutamic acid decarboxylase mRNA levels in the striatum and pallidum of MPTP-treated primates. J Neurosci 14:6256-6265.

Soltis RP, Anderson LA, Walters JR, Kelland MD (1994) A role for non-NMDA excitatory amino acid receptors in regulating the basal activity of rat globus pallidus neurons and their activation by the subthalamic nucleus. Brain Res 666:21-30.

Takada M, Nishihama MS, Nishiliama CC, Hattori T (1988) Two separate populations of the rat subthalamic nucleus project to the basal ganglia and pedunculopontine tegmental region. Brain Res 442:7280 .

Thompson LA, Walters JR (1993) Influence of excitatory amino acid antagonists and dopamine agonists on the firing rate of subthalamic nucleus neurons. Soc Neurosci Abstr 19:781.

Van der Kooy D, Hattori T (1980) Single subthalamic nucleus neurons project to both the globus pallidus and substantia nigra in rat. J Comp Neurol 192:751-768.

Vignon J, Pinet V, Cerruti C, Kamenka JM, Chicheportiche R (1988) $\left[{ }^{3} \mathrm{H}\right] \mathrm{N}-\left[1\right.$-(2-benzo(b)thiophenyl)cyclohexyl]-piperidine $\left(\left[{ }^{3} \mathrm{H}\right] \mathrm{BTCP}\right)$ : a new phencyclidine analog selective for the dopamine uptake complex. Eur J Pharmacol 148:427-436.

Wooten GF, Collins RC (1981) Metabolic effects of unilateral lesion of the substantia nigra. J Neurosci 1:285-291.

Wüllner U, Testa CM, Catania MV, Young AB, Penney JB Jr (1994) Glutamate receptors in striatum and substantia nigra: effects of medial forebrain bundle lesions. Brain Res 645:98-102.

Yoshikawa K, Williams C, Sabol SL (1984) Rat brain preproenkephalin mRNA. J Biol Chem 259:14301-14308.

Zetterström T, Herrera-Marschitz M, Ungerstedt U (1986) Simultaneous measurement of dopamine release and rotational behaviour in 6-hydroxydopamine denervated rats using intracerebral dialysis. Brain Res 376:1-7. 